Solid Earth Discuss., https://doi.org/10.5194/se-2019-4

Manuscript under review for journal Solid Earth

Discussion started: 15 January 2019

(C) Author(s) 2019. CC BY 4.0 License.

\title{
Bayesian geological and geophysical data fusion for the construction and uncertainty quantification of 3D geological models
}

Hugo K. H. Olierook ${ }^{1}$, Richard Scalzo², David Kohn³, Rohitash Chandra ${ }^{2,4}$, Ehsan Farahbakhsh",4, Gregory Houseman³ ${ }^{3}$ Chris Clark¹, Steven M. Reddy¹, R. Dietmar Müller ${ }^{4}$

$5 \quad{ }^{1}$ School of Earth and Planetary Sciences, Curtin University, GPO Box U1987, Perth, WA 6845, Australia

${ }^{2}$ Centre for Trans lational Data Science, University of Sydney, NSW 2006 Sydney, Australia

${ }^{3}$ Sydney Informatics Hub, University of Sydney, NSW 2006 Sydney, Australia

${ }^{4}$ EarthByte Group, School of Geosciences, University of Sydney, NSW 2006 Sydney, Australia

Correspondence to:Hugo K. H. Olierook(hugo.olierook@curtin.edu.au)

10 Abstract. Traditional approaches to develop 3D geological models employ a mix of quantitative and qualitative scientific techniques, which do not fully provide quantification of uncertainty in the constructed models and fail to optimally weight geological field observations against constraints fromgeophysical data. Here, we demonstrate a Bayesian methodology to fuse geological field observations with aeromagnetic and gravity data to build robust 3D models in a $13.5 \times 13.5 \mathrm{~km}$ region of the Gascoyne Province, Western Australia. Our approach is validated by comparing model results to independently-constrained geological maps and cross-sections produced by the Geological Survey of Western Australia. By fusing geological field data with magnetics and gravity surveys, we show that at $89 \%$ of the modelled region has $>95 \%$ certainty. The boundaries between geological units are characterized by narrow regions with $<95 \%$ certainty, which are typically $400-1000$ m wide at the Earth’s surface and 500-2000 m wide at depth. Beyond $\sim 4 \mathrm{~km}$ depth, the model requires drill hole data and geophysical survey data with longer wavelengths (e.g., active seismic) to constrain the deeper subsurface. Our results show that surface geological observations fused with geophysical survey data yield robust 3D geological models with narrow uncertainty regions at the surface and shallow subsurface, which will be especially valuable for mineral exploration and the development of 3D geological models under cover.

\section{Introduction}

25 Surface mapping and subsurface interpretation of geological units is one of the tenets of the geological and geophysical community. Geological units and their as sociated boundaries may share similar geological histories or may be juxtaposed to one another via structural discontinuities such as faults or suture zones. Accurately positioning geological units and their boundaries is fundamental for, and not limited to, constraining plate reconstructions (Cawood and Korsch, 2008; Merdith et al., 2017), defining stratigraphy (Gradstein et al., 2012), and successful mineral and petroleum exploration (Dentith and

30 Mudge, 2014; Selley and Sonnenberg, 2014). In order to conceive a comprehensivemodel of both the surface and subsurface geology, a combination of geological mapping, geophysical interpretation, sample analysis and prior knowledge are used. 
Solid Earth Discuss., https://doi.org/10.5194/se-2019-4

Manuscript under review for journal Solid Earth

Discussion started: 15 January 2019

(c) Author(s) 2019. CC BY 4.0 License.

Although all of these ingredients are important, contemporary workflows to incorporate themall tend to develop at best only a handful of possibly biased solutions that either neglect, or incompletely account for, the uncertainty associated with geological or geophysical interpretation, as well as the knowledge of how far to extrapolate data derived from sample analysis. This shortcoming of traditional geological model-building is exacerbated in regions with thick sedimentary or regolith 'cover'

5 because this poses a significant impediment to understanding thenature of the subsurface.

To develop robust geological models, it is important to quantify theuncertainty on the position and configuration of geological units. Previous work addressing the uncertainty problem included employing fuzzy logic and information entropy approaches to build semi-quantitative3D geological models (Abedi and Norouzi, 2012; Joly et al., 2012; Wellmann and Regenauer-Lieb,

10 2012). However, these approaches still require a significant degree of human decision making into how to fuse disparate geos cientific datasets. Other approaches characterize uncertainty by generating ensembles of 3D models through perturbations of a set of underlying descriptive geometric parameters (de la Varga et al., 2018; Giraud et al., in review; Lindsay et al., 2013; Pakyuz-Charrier et al., 2018). However, these approaches still largely elide the question of how the joint distribution of such parameters is meant to be derived. A fully quantitative and informative3D geological model will fuse all available constraints in a probabilistically rigorous fashion. Bayesian inference provides a suitable framework for doing this by using Markov chain Monte Carlo (MCMC) sampling methods for estimation and uncertainty quantification of free parameters. Previous studies using Bayesian inference in the geosciences have focused on (i) geophysical joint inversions (Bosch et al., 2006; Giraud et al., 2017; Shen et al., 2013), (ii) fluid flow through permeable reservoirs for groundwater, hydrocarbon or carbon dioxide storage applications (Oladyshkin et al., 2013; Refsgaard et al., 2012; Seifert et al., 2012; Ye et al., 2010), and (iii) geomorphologic and climate evolution (Chandra et al., 2018; Hapke and Plant, 2010; Pall et al., 2018). However, there is still a paucity of work in fusing solid Earth geological observations and geophysical data in a Bayesian framework to develop robust 3D geological models.

The Obsidian software package provides a workflow to fuse disparate geological and geophysical data within a Bayesian framework (McCalman et al., 2014; Reid et al., 2013). Obsidian features a parameterized world model of the 3D structure and physical properties of geological formations. Here, the free parameters are estimated by MCMC with the sampling taking into account both the estimated prior probability of the existence of any particular formation, and the likelihood of that configuration producing all available geophysical survey data in the modelled region. Obsidian was originally designed for deep ( 1-5km) geothermal energy applications in sedimentary basins, which includes the ability to fuse airborne or surface geophysical surveys (e.g., aeromagnetics, gravity, magnetotellurics, temperature) with laterally-sparse geophysical drill hole data (e.g., geological unit depths, bore hole temperature, density) and drill hole geological units as prior points. One useful addition to the current features of Obsidian would be the integration of geological and geophysical field observations made on theEarth's surface, which are vital for surface and near-surface applications $(<1 \mathrm{~km})$. Such applications include the mineral exploration sector but also extend to any igneous or metamorphic ('hard-rock') terranes. Unlike sparse drill hole data, surface geological 
Solid Earth Discuss., https://doi.org/10.5194/se-2019-4

Manuscript under review for journal Solid Earth

Discussion started: 15 January 2019

(c) Author(s) 2019. CC BY 4.0 License.

and geophysical observations provide high-resolution lateral constraints on 2D surface geological models that, together with geophysical survey data, permit the development of robust 3D geological models.

In this contribution, we extend the Obsidian software package to enable coupling of (i) airborne magnetic and gravity survey

5 data (using petrophysical priors derived from surface samples) with (ii) geological field observations that inform the configuration of geological units at discrete points on the Earth's surface. We demonstrate the validity of our techniques by building models of a data-rich, $13.5 \times 13.5 \mathrm{~km}$ subsection of the Gascoyne Province, Western Australia, and comparing the model results to surface geological maps produced by the Geological Survey of Western Australia (GSWA) and subsurface interpretations (Johnson et al., 2013). The chosen study area is particularly suitable as it also exhibits a significant portion of

10 recent sedimentary and regolith cover, which makes certain areas inaccessible for recording geological surface observations directly but possible to infer using Bayesian techniques. We anticipate that this framework provides a foundation for future applications in igneous and metamorphic terranes, particularly in the mineral exploration sector and especially in exploration under cover (McFadden et al., 2012).

\section{$15 \quad 2 \quad$ Background}

\subsection{Geological setting of the Gascoyne Province}

The Gascoyne Province, and the wider Capricorn Orogen, record the protracted amalgamation of the West Australian Craton and subsequent intracontinental tectonothermal activity (Fig. 1, Fig. 2). Two main events are thought to contribute to forming the West Australian Craton. First, the ca. 2195-2145 Ma Ophthalmia Orogeny sutured the Glenburgh Terrane, comprised of the Halfway Gneiss, to the Pilbara Craton (Krapežet al., 2017; Rasmussen, 2005). The deposition of the Moogie Metamophics was associated with the Ophthalmia Orogeny, deposited into a foreland basin that formed in a response to the GlenburghPilbara collision (Johnson et al., 2013). Second, the ca. 2005-1950 Ma Glenburgh Orogeny then amalgamated the combined Pilbara Craton-Glenburgh Terrane with the Yilgarn Craton to form the West Australian Craton (Johnson et al., 2013; Olierook et al., 2018). The Glenburgh Orogeny was associated with two major Andean-type granitoid formations, the Dalgaringa and Bertibubba Supersuites, and several subduction-related basins (Johnson et al., 2011; Olierook et al., 2018). After unification, the Capricorn Orogen experienced at least five intracontinental tectonomagmatic events, each decreasing in severity of tectonic character and magmatism(Johnson et al., 2017). The first two events, the 1830-1780 Ma Capricorn Orogeny and 1680-1620 Ma Mangaroon Orogeny, were both associated with significant granitoid magmatism of the Moorarie and Durlacher Supersuites, respectively (Sheppard et al., 2010a; Sheppard et al., 2005). Deposition of the Leake Springs Metamorphics was

30 also concurrent with the early stages of the Capricorn Orogeny. Later events were predominantly amagmatic but were still associated with up to amphibolite-facies metamorphism and hydrothermal activity (Korhonen et al., 2017; Sheppard et al, 2007). Both suturing and intracontinental tectonic events have developed a pervasiveeast-west striking structural fabric in the 
Solid Earth Discuss., https://doi.org/10.5194/se-2019-4

Manuscript under review for journal Solid Earth

Discussion started: 15 January 2019

(c) Author(s) 2019. CC BY 4.0 License.

Gascoyne Province that has compartmentalized the region into several geological zones that share tectonic characteristics (Sheppard et al., 2010a). In the south, zone and formation boundaries trend NE-SW whereas major structures are oriented NW-SE in the north, yielding a wedge-shaped geometry for the Gascoyne Province (Fig. 1, Fig. 2). Compared to the rest of the Capricorn Orogen, the Gascoyne Province is relatively well exposed but there are still significant areas covered by recent

5 regolith and sediment that hamper mineral exploration.

\subsection{Bayesian inversion and inference}

Inverse problems aimto recover the causal factors that produced a set of observations (Mosegaard and Tarantola, 1995; Sambridge and Mosegaard, 2002). For geological and geophysical applications, theobjective of inverse problems is to recover the subsurface properties such as density and magnetic susceptibility fromsurface-based geophysical survey measurements of gravity and magnetic field strength. However, geophysical surveys cannot yield unique solutions of the subsurface petrophysical properties. Thus, there are an infinite number of subsurface petrophysical measurement configurations that would produce the same survey readings (Sambridge, 1999; Sambridge and Mosegaard, 2002). Given that there is no single unique solution, there is no reason to prefer one model over another without introducing constraints on what form the model should take (Parker, 1977; Sambridge and Mosegaard, 2002). Ways to introduce such constraints include regularization (Giraud et al., in review) but this technique fails to acknowledge alternative scenarios. A probabilistic interpretation casts the problemin terms of maximizing the likelihood or a posteriori probability of the model, but the fact remains that multiple qualitatively different solutions may be equivalently accessible to the data (Mosegaard and Vestergaard, 1991; Rocca et al., 2009).

An alternative approach is to use sampling over all possible models in a probabilistic Bayesian context, which provides a more systematic approach towards uncertainty quantification and the incorporation of prior constraints. Bayesian inference can be applied to parametric (Shafer, 1982) and nonparametric models (Hjort et al., 2010). Bayesian methods have become more popular in geophysics in the past few decades (Malinverno, 2002; Mosegaard and Tarantola, 1995; Sambridge and

25 Mosegaard, 2002; Sambridge and Compston, 1994). The strategy of obtaining free parameters that fit the data in geophysical models have shifted fromoptimization (Sen and Stoffa, 2013) to inference that addresses uncertainty quantification given that the models provide an approximation of geophysical processes (Gallagher et al., 2009). The Bayesian framework converts a deterministic model into a probabilistic one by using probability distributions to represent the free parameters rather than using optimal or single-point estimates. This takes into account observed data and prior information (priors) about themodel parameters (Oldenburg 2005). The prior information about model parameters is presented in the formof a probability dis tribution (e.g., density and magnetic susceptibilities; Backus, 1970). The likelihood function evaluates the quality of the proposal for the free parameters by taking into account the forward model output, given data and noise in model outputs (Guillaume et al., 2013; Kaipio and Somersalo, 2006). The priors and likelihood functions multiply to give 
Solid Earth Discuss., https://doi.org/10.5194/se-2019-4

Manuscript under review for journal Solid Earth

Discussion started: 15 January 2019

(c) Author(s) 2019. CC BY 4.0 License.

solutions to the inverse problem, which is referred to as theposterior distribution (Kaipio and Somers alo, 2006; Oldenburg and $\mathrm{Li}, 2005)$.

The approximation of the posterior distribution by MCMC methods is computationally expensive since thousands of model

5 evaluations are required to iteratively sample the posterior distribution (Sen and Stoffa, 1996; Tarantola and Valette, 1982). To do this, samples (proposals) are drawn from a target distribution by constructing a Markov chain that, after a number of steps, converges to the desired distribution as its reaches equilibrium (Hastings, 1970; Kass et al., 1998; Metropolis et al, 1953; Raftery and Lewis, 1996; van Ravenzwaaij et al., 2018). Convergence criteria determine when to stop sampling that, for example, could be a predetermined number of samples or an assessment of the behaviour of the likelihood function. However, for complex and large-scale 3D inversion problems, convergence can be challenging due to the largenumber of free parameters that need to be sampled effectively in limited computation time (i.e., high dimensionality; Sen and Stoffa, 1996).

For multimodal posteriors, the Markov chain can become trapped in a single mode and cannot fully explore the postenior distribution, making sampling much less efficient or causing the chain to converge to the wrong distribution. Parallel tempening (PT) is a sophisticated MCMC method that aims to increase the efficiency of the exploration of multimodal postenior distributions (Geyer, 1993; Hukushima and Nemoto, 1996; Sambridge, 2013). Parallel tempering uses a number of replicas of the original sampling method, where the replicas are created at different 'temperatures’' (Brooks et al., 2011; Earl and Deem, 2005) by rescaling the likelihood probability density function (Sambridge, 2013). High temperature replicas sample a smoother (flatter) version of the likelihood function in order to 'escape' from local minima and provide global exploration features.

Convers ely, low temperature replicas providelocal exploration capabilities. Hence, with parallel tempering, there is a delicate balance between global and local exploration (Earl and Deem, 2005; Sambridge, 2013). During sampling, the replicas are able to exchange their configurations, typically between neighbouring replicas via the Metropolis-Hastings proposal(Sambridge, 2013). Ultimately, this improves themixing of Markov chain (i.e. thorough exploration of space and convergenceto the target distribution) and efficiency of convergence (Sambridge, 2013).

25

\subsection{Obsidian software package for joint geophysical inversion}

The Obsidian software package was originally designed for geothermal exploration in sedimentary basins. Here, we provide a brief overview of the salient features that are important for our inverse problem(Fig. 3). For a detailed background of Obsidian, the reader is referred to Ramos et al. (2012), Reid et al. (2013), McCalman et al. (2014), Beardsmore et al. (2016) and Scałzo et al. (in review).

The modelled area in Obsidian is parameterized as a series of discrete layers, each with its own spatially constant rock properties, separated by smooth geological boundaries (Fig. 3a, b; Beardsmore et al., 2016; McCalman et al., 2014). Each 
Solid Earth Discuss., https://doi.org/10.5194/se-2019-4

Manuscript under review for journal Solid Earth

Discussion started: 15 January 2019

(c) Author(s) 2019. CC BY 4.0 License.

geological layer boundary is a 2D Gaussian process regression against a set of user-defined control points $\left(\alpha_{n}\right.$ in Fig. 3a) that specify the subsurface depth of the boundary at given surface locations. The layer boundaries are indexed in a strict order of increasing depth in the subsurface but are permitted to cross. For each layer, the control point depth offsets have a multivariate Gaussian prior with mean zero and a specific covariance between the control points for that layer (Fig. 3a). For each layer, our

5 inverse problem comprises: (i) parameters for the offset of the mean depth from the top of that layer at each control point position, and (ii) rock properties for each geophysical survey (e.g., magnetic susceptibility property for aeromagnetic field strength, $\rho_{n}$ in Fig. 3a).

The Gaussian processes that interpolate the layer boundaries across the lateral extent of the modelled volume use a radial basis function kernel with a mean function that varies by the layer and fixed $\mathrm{x}$ and $\mathrm{y}$ correlation lengths (Fig. 3c; Beardsmore et al, 2016; McCalman et al., 2014). These correlation lengths are fixed to the spacing between control point locations. The rock properties (e.g., magnetic susceptibility) for each layer are independent of the control points and havea multivariate Gaussian prior. For each geophysical survey (e.g., aeromagnetics), the likelihood is Gaussian but thevariance of the 'noise' is as sumed to follow an inverse gamma distribution with user-specified hyper parameters that definethe shape of the distribution. When the noise hyper parameters are integrated via sampling, the resulting likelihood when marginalized over an inverse gamma prior is a Student's $t$ with $2 \alpha$ degrees of freedomand a scale of $\beta / \alpha$ for the observations.

The PTMCMC algorithm embedded in the Obsidian software package optimizes the mean acceptance rate of the swaps between the chains in adjacent temperatures by continuously adapting the scale parameter of the proposal distribution (i.e., the estimated covariance of the target dis tribution at each temperature) during the simulation (Beardsmore et al., 2016; Mias ojedow et al., 2013). This continuous adaptation - known as adaptive parallel tempering MCMC-allows the algorithmto learn the progressive adjustment of step size used for proposals within each chain as well as the temperature ladder used to sample across chains (Andrieu and Thoms, 2008). The maximum allowed change to any chain property diminis hes over time, inversely proportional to the number of samples to ensure convergence(Andrieu and Thoms, 2008).

\section{$3 \quad$ Materials and Methods}

\subsection{World parameterization}

The construction of theparameterized world model in the chosen $13.5 \times 13.5 \mathrm{~km}$ area in the GascoyneProvince involves three types of data: a hierarchical construction of layers using available 2D seismic data interpretation(Fig. 1b; Johnson et al., 2013)

30 and two types of point-based measurements — magnetic and density data — on hand samples from Aitken et al. (2014). A two-dimensional seismic survey was conducted in 2011 (Johnson et al., 2013). The surface position of the seismic line is immediately to the west of our study area and cross-cuts the same geological units (Fig. 1a). The seismic interpretation of 
Solid Earth Discuss., https://doi.org/10.5194/se-2019-4

Manuscript under review for journal Solid Earth

Discussion started: 15 January 2019

(c) Author(s) 2019. CC BY 4.0 License.

Johnson et al. (2013), aided by geochronological data, directly informs that the ordering of layers in the world model, from oldest to youngest, are: (i) the ca. 2550-2430 Ma Halfway Gneiss (Johnson et al., 2017), (ii) ca. 2210-2150 Ma Moogie Metamorphics (Martin and Morris, 2010), (iii) ca. 1840-1810 Ma Leake Spring Metamorphics and ca. 1830-1780 Ma Moorarie Supersuite (Johnson et al., 2011; Sheppard et al., 2010b), (iv) ca. 1690-1660 Ma Durlacher Supersuite (Piechocka

5 et al., 2017; Sheppard et al., 2005), and (v)ca. 995-900 Ma Thirty Three Supersuite (Piechocka et al., 2017; Sheppard et al, 2010b). In the chosen $13.5 \times 13.5 \mathrm{~km}$ area, only the Halfway Gneiss and Durlacher Supersuite are areally significant, comprising $\sim 59 \%$ and $~ 35 \%$ of the interpreted area by GSWA (Fig. 2). Other areally-minor units in the $13.5 \times 13.5 \mathrm{~km}$ area include the Leake Spring Metamorphics ( 3\%), Moogie Metamorphics ( 2\%), Moorarie Supersuite ( $<1 \%)$ and Thirty Three Supersuite $(<1 \%)$.

10

\subsection{Petrophysical data}

Two types of petrophysical data, magnetic susceptibility and density, were collected on hand samples (Aitken et al., 2014) to link to aeromagnetic and gravity data, respectively (Fig. 4). A relatively low number of magnetic $(n=104)$ and density $(n=$ 103) samples across the entire Gas coyne Province were available (Aitken et al., 2014). Thus, the sample mean and covariance

15 of magnetic and density measurements for each geological unit were used to inform a multivariate Gaussian prior, acknowledging that spatial differences in magnetic and density distributions cannot be captured in this contribution.

\subsection{Geophysical and geological data}

Two geophysical survey data are employed, namely aeromagnetic (Fig. 5a) and gravity data (Fig. 5b), that are forwardmodelled to correspond to sample-based magnetic and density data, respectively. These types of geophysical surveys were already available for Bayesian fusion in the Obsidian framework. In addition to the geophysical data, field-bas ed geological units observations are incorporated into Obsidian(Fig. 5c).

Aeromagnetic data in the study area(Fig. 5a) utilized a subsection of the 1995/96 Bangemall Survey directed by GSWA from latitudes 23.5-26.0 $0^{\circ}$ and longitudes 115.0-120.0 E (Geological Survey of Western Australia, 1996). The Bangemall aeromagnetic data were flown at a $7.5 \mathrm{~m}$ sample interval, $500 \mathrm{~m}$ flight line spacing and a mean terrain clearance of $60 \mathrm{~m}$. The final magnetic intensity in nT has the following corrections from the raw data:(i) the 1990 IGRF model removed and a base value of $54940 \mathrm{nT}$ added, (ii) diurnal correction applied, with a base value of $55220 \mathrm{nT}$, (iii) parallax correction of 0.4 fiducial applied, (iv) levelled using tie line information, and (v) tie lines force levelled to flight lines. The original horizontal datum of the Bangemall Survey was the AGD84, projected using AMGzone 50, but this was converted to the WGS84, zone $50 \mathrm{~S}$ for each data point. The flight path vector data were explicitly favoured over the post-processed raster data to avoid introducing correlations. 
Solid Earth Discuss., https://doi.org/10.5194/se-2019-4

Manuscript under review for journal Solid Earth

Discussion started: 15 January 2019

(c) Author(s) 2019. CC BY 4.0 License.

Gravity anomaly data in the study area (Fig. 5b) were derived from the 2010 Gascoyne North and Gascoyne South surveys directed by GSW A from latitudes 23.5-26.0 $\mathrm{S}$ and longitudes 115.2-118.5 ${ }^{\circ} \mathrm{E}$ (Mathews and Jecks, 2010). The Gascoyne North and South gravity data were acquired at a ground-based nominal station spacing of $2500 \mathrm{~min}$ a square grid configuration.

5 The final complete spherical cap Bouguer anomaly in $\mu \mathrm{ms}^{-2}$ had the following corrections from the raw data: (i) correction of remanent drift, typically less than $0.05 \mu \mathrm{ms}^{-2} \mathrm{hr}^{-1}$, (ii) computation of Bouguer anomaly using a modified spreadsheet developed by M. Bacchin of Geoscience Australia, (iii) spherical cap Bouguer anomaly computation relative to the Australian Absolute Gravity Datum 2007, and (iv) terrain correction using the AUSGEOID09 vertical coordinate reference frame. The original horizontal datumwas GDA 94, which is equivalent to WGS84. The located surface point-based data were explicitly

10 favoured over the post-processed raster data. Very finely, regularly-sampled raster data are often preferred in order to apply fast Fourier transforminvers ion techniques. However, res ampling or interpolating non-gridded data onto such a grid results in correlations between the gridded data points, which can lead to biases and incorrect results in probabilistic inversions if not explicitly accounted for (Scalzo et al., in review).

15 Surface geological unit observations were acquired from the Western Australian Rocks (WAROX) database, available from GSWA (Fig. 2, Fig. 5c). Each spatially-referenced sample point records an observation of rocktype coupled to an interpreted geological unit. Designation of a particular geological unit is informed frompetrographic, geochemical and geochronological knowledge obtained on a subset of W AROX data. For example, the assignment of a geological unit is near certain where U$\mathrm{Pb}$ crystallization ages are available or where whole-rock major and trace element geochemistry has been collected. In the chosen $13.5 \times 13.5 \mathrm{~km}$ study area, only one sample has geochronological and geochemical information (Fig. 5c). However, there are $>100$ age and $>500$ samples with geochronological and geochemical data, respectively, in the Gascoyne Province from the same geological units that are present in the $13.5 \times 13.5$ study area (e.g., Johnson et al., 2017). All samples with U$\mathrm{Pb}$ ages and/or geochemical data in the Gascoyne Province als o have petrographic and/or hand sample descriptions, which can be used to inform the geological unit for geological surface observations where only hand sample or petrographic descriptions are available. Even though inference of geologicalunits fromsimilar petrographic and hand sample descriptions is relatively robust, it may be in error. Thus, we have accounted for this potential uncertainty in geological field observations (see section 3.4 for further details). All our observations were taken at the surface but could be readily used where geological unit observations could be made in the subsurface (i.e., via drill hole information). The formation that is observed at the surface defines the value of a given field observation.

\subsection{Likelihoodmodels}

We use Gaussian likelihood distributions for gravity and aeromagnetic surveys, which assumes that the residuals from the respective forward models are thems elves Gaussian. Themean of each survey’s Gaussian likelihood is given by the output of 
Solid Earth Discuss., https://doi.org/10.5194/se-2019-4

Manuscript under review for journal Solid Earth

Discussion started: 15 January 2019

(c) Author(s) 2019. CC BY 4.0 License.

the respective survey's forward models. The unknown variance of each Gaussian likelihood distribution is drawn from an invers e gamma prior, with survey-specific shape parameters. For both the gravity and magnetismsurvey data, we set the noise $\alpha$ to 1 and the noise $\beta$ to 0.2 . The inverse gamma priors allow us to incorporate uncertainty for the noise for the survey likelihoods. We assume that the likelihoods are conditionally independent given the world model output (McCalman et al, 5 2014).

We use a binomial likelihood for the field observations and we put a Beta prior probability distribution on the probability of success for the binomial model. The binomial likelihood is defined as:

$$
P(k \mid n, p)=\frac{\Gamma(n+1)}{\Gamma(k+1) \Gamma(n-k+1)} p^{k}(1-p)^{n-k}
$$

10 where $k$ is the number of successes, $n$ is the number of trials, $p$ is the probability of success for each trial and $\Gamma$ is the gamma function. The left fraction is the binomial coefficient and is more commonly written as $\left(\begin{array}{l}n \\ k\end{array}\right)$ but the gamma function representation generalizes to non-integers. With a Beta hierarchical prior on $p$, we can write:

$$
\begin{aligned}
P(k \mid n, \alpha, \beta)= & \frac{\Gamma(n+1)}{\Gamma(k+1) \Gamma(n-k+1)} \int_{0}^{1} p^{k}(1-p)^{n-k}\left[\frac{p^{\alpha}(1-p)^{\beta}}{B(\alpha, \beta)}\right] d p=\frac{\Gamma(n+1)}{\Gamma(k+1) \Gamma(n-k+1)} \frac{\Gamma(k+\alpha) \Gamma(n-k+\beta)}{\Gamma(n+\alpha+\beta)} \\
& +\frac{\Gamma(\alpha) \Gamma(\beta)}{\Gamma(\alpha+\beta)}
\end{aligned}
$$

15 The Beta distribution is a dis tribution that takes on values between zero and one and has two shape parameters, $\alpha$ and $\beta$. For the field observation likelihood distribution, we set the noise $\alpha$ to 20 and the noise $\beta$ to 1 , resulting in a 95\% credible lower limit of getting at least $85 \%$ correct observations in the field ID dataset. Using a Beta prior results in an analytically tractable likelihood that captures potential overdis persion in the field observations. Overdispersion could be a problemif there is more than one source of variation in the error of the observations, such as distinct geologists interpreting rock formations differently

20 (Gelman et al., 2013).

\subsection{Markov chain Monte Carlo sampling}

We use PT-MCMC to explore the parameter space, which is limited by our world parameterization. We can use different types of PT-MCMC proposals that to varying degrees must maintain the properties of the Markov chain to ensure convergence to the target distribution. The original Obsidian implementation used an isotropic Gaussian random walk (iGRW) proposal (Beardsmore et al., 2016; McCalman et al., 2014). To increase the efficiency of our sampler as to draw less correlated and more independent samples, we instead use the preconditioned Crank-Nicols on MCMC proposal, which weights between a Gaussian random walk proposal and a draw from the prior (Cotter et al., 2013; Hu et al., 2017; Rudolf and Sprungk, 2018). Further details of our implementation can be found in Scalzo et al. (in review). 
Solid Earth Discuss., https://doi.org/10.5194/se-2019-4

Manuscript under review for journal Solid Earth

Discussion started: 15 January 2019

(c) Author(s) 2019. CC BY 4.0 License.

\subsection{Experiment Design}

We run the Obsidian PT-MCMC with sixparallel tempering temperature ladders (stacks), where each stack consists of twelve PT-MCMC chains. The likelihood of each chain is rais ed to the power of a different temperature in the ladder and the lowest temperature chain is the unnormalized likelihood. Samples are only collected for the lowest temperature chain. This setup has

5 enough chains in each ladder to ensure geometric spacing between temperatures on the ladder, confirmed by empirical examination of the ladder, and has enough stacks to ensure sufficient confidence in the convergence diagnostics, specifically the potential scale reduction factor diagnostic. The experiment was run on an area of $13.5 \mathrm{x} 13.5 \mathrm{~km}$ for 96 hours to ensure convergence for all rock property and control point parameters.

\section{Results}

\subsection{Convergence diagnostics}

Convergence diagnostics aid in evaluating whether the MCMC sampling has converged (i.e., whether sampling is occurring from the target distribution; Gelman et al., 2013). Convergence of the control point parameters occurred after only 12 hours but the rock property parameters required approximately half of the total 96-hour run time to reach convergence. Several techniques are listed here to confirm that our model outputs are statistically-valid, including (i) trace plots of the MCMC samples (Fig. 6a, b, Table 1), (ii) autocorrelation times and effective sample size (Fig. 6c, Table 1), (iii) potential scale reduction factor (Table 1), and (iv) Geweke score (Fig. 7).

Trace plots for modelled density and magnetic susceptibility show that: (a) chains initialized at different initial states have similar posterior densities, and (b) chains mix well, i.e., they sufficiently explore the support of the posterior dis tributions as determined by the parameters' respective priors (first column in each panel of Fig. 6). The Halfway Gneiss and Durlacher Supersuite have modelled densities of $2.72 \pm 0.12$ and $2.67 \pm 0.12 \mathrm{~g} \mathrm{~cm}^{-3}(2 \sigma)$, respectively, and average modelled $\log _{10}$ magnetic susceptibilities of $-3.65 \pm 0.57$ and $-2.60 \pm 0.07(2 \sigma)$, respectively (second column in each panel of Fig. 6). Compared to the Halfway Gneiss, a lower magnetic mean susceptibility and larger variance in magnetic susceptibility for the Durlacher

25 Supersuite agrees with the prior density and magnetic measurements for both formations (Fig. 4). The lack of difference between themodelled densities of the Halfway Gneiss and Durlacher Supersuite (at $2 \sigma$ ) are also in agreement with the priors (Fig. 4).

There are approximately 1.5 million total samples for each chain. However, samples from MCMC are correlated (third column

30 in each panel of Fig. 6), which reduces the number of independent samples (i.e., the effective sample size) from the postenior distribution (Gelman et al., 2013). The MCMCautocorrelation is on the order of 1 in 12 to 1 in 14 independent samples per 
Solid Earth Discuss., https://doi.org/10.5194/se-2019-4

Manuscript under review for journal Solid Earth

Discussion started: 15 January 2019

(c) Author(s) 2019. CC BY 4.0 License.

MCMC proposal for rock property parameters and 1 in 1 to 1 in 15 independent samples for control point parameters (Table 1). This means that there are approximately 105,000-129,000 and 100,000-1,000,000 independent samples for the rock property and control point parameters, respectively.

5 The potential scale reduction factor (PSRF), als o known as the Gelman-Rubin statistic or $\hat{R}$ (Gelman and Rubin, 1992), assesses convergence by comparing the variance between means of multiple chains relative to the average of the variance within chains to show how much an estimator of the marginal posterior variance will decrease as the number of samples increases (Brooks and Gelman, 1998; Cowles and Carlin, 1996). If the diagnostic is close to 1 then limited reductions in variance can be made from further sampling and the sampling has likely converged to the target distribution. All of our rock property and control point parameters have $\hat{\mathrm{R}}=1.02-1.03$ and $\hat{\mathrm{R}}=1.00-1.06$, respectively (Table 1 ), which indicate convergence on thebasis that the Gelman-Rubin statistic is less than the threshold of 1.10 (Gelman et al., 2013).

The convergence of the target distribution may also be evaluated using the Geweke score (Geweke, 1991), which is a z-score diagnostic that compares the mean of subsets of samples from the start and end of the MCMC chains. A heuristic for convergence are Geweke scores between -2 and +2, indicating normality of the difference in means (Cowles and Carlin, 1996). We see convergence of our chains in terms of this diagnostic with Geweke scores of and -1 to +1 and -0.5 to 1.5 for the density and magnetic susceptibility parameters, respectively, except for two chains (chain 2, density for both formations) which show large deviations (Fig. 7).

\subsection{Residuals fromforward models}

Aeromagnetic and gravity models from forward models are broadly comparable to their measured counterparts (Fig. 8a, d). Aeromagnetic models effectively identify the NW-SE strike of magnetic lineaments in the northern half of the modelled volume (Fig. 2, Fig. 8). The NE-trending elongate unit in the southern half of the map, corresponding to the Durlacher Supersuite (Fig. 2), also shows limited discrepancies between modelled and measured data (Fig. 8). Aeromagnetic residuals display an approximately Gaussian distribution of $0_{-317}^{+358} \mathrm{nT}(2 \sigma, 21 \%$ of the total magnetic range; Fig. 8). Only one region in the northwestern portion of the map has significantly higher magnetic field strength than modelled (Fig. 8).

Modelled gravity effectively identify the long-wavelength, $\mathrm{N}-\mathrm{S}$ trending structure in the measured data but there are significant positive residuals in the south-west corner and negative residuals in the central-eastern portion of the modelled area (Fig. 2, Fig. 8). Gravity residuals are positively skewed with a residual of $0_{-2.36}^{+3.96} \mathrm{mGal}(2 \sigma, 20 \%$ of the total gravity range; Fig. 8). 
Solid Earth Discuss., https://doi.org/10.5194/se-2019-4

Manuscript under review for journal Solid Earth

Discussion started: 15 January 2019

(c) Author(s) 2019. CC BY 4.0 License.

The forward modelled field observations have a posterior probability of success of approximately 80\% (Fig. 9a-c). Five of 141 actual Halfway Gneiss observations have been misclassified as belonging to the Durlacher Supersuite, while most of the actual Durlacher Supersuite observations have been misclassified as belonging to Halfway Gneiss (Fig. 9d-f). All the misclassifications occur within $1 \mathrm{~km}$ of boundaries between geological units, particularly in the southeast and eastern parts of 5 the $13.5 \times 13.5 \mathrm{~km}$ area(Fig. 9e).

\subsection{Probability density of layer locations}

Voxelized posterior dis tributions of the modelled volume reveal a strong probability contrast between regions of high certainty (defined as $>95 \%$ ) at the surface (Fig. 10). Two modelled volume shows that the Durlacher Supersuite occupies the northeastern section of the region and an ellipsoidal inlier towards the southern extent of the $13.5 \times 13.5 \mathrm{~km}$ map (Fig. 10). The remainder of the map shows Halfway Gneiss. For the NE-SW boundary between the modelled Durlacher Supersuite and Halfway Gneiss, the distance between $>95 \%$ certainty of Halfway Gneiss and Durlacher Supersuite (i.e., region with $<95 \%$ confidence) equates to horizontal distances of $\sim 300-1000 \mathrm{~m}$ at the surface. The ellipsoidal Durlacher Supersuite inlier is heterogeneously constrained. The horizontal distance for the boundary between the Durlacher Supersuite and Halfway Gneiss

$15(<95 \%)$ is relatively tightly constrained along the NW and SW margins ( $\sim 50 \mathrm{~m})$, moderately constrained along the SE margin ( 750-1100 m) and poorly constrained towards the east(up to 2350 m; Fig. 10).

At depth, sub-vertical unit boundaries are maintained as informed by theprior (Figs. 1, 2; seismic interpretation of Johnson et al., 2013). The modelled cross-section yields dips of $85^{\circ}$ near the surface, and progressively reducing in inclination to $\sim 72^{\circ}$ at

$204 \mathrm{~km}$ depth. In the cross-section, the horizontal distance between regions of $>95 \%$ certainty between the Halfway Gneiss or Durlacher Supersuite becomes progressively more diffuse, from $\sim 20 \mathrm{~m}$ to $1060 \mathrm{~m}$ between the surface and $4 \mathrm{~km}$ depth, respectively (Fig. 11). This translates to a percentage decrease in horizontal confidence of $\sim 250 \%$. In other parts of the 3D model, regions of $<95 \%$ certainty canbe as wide as $\sim 2500 \mathrm{~m}$ at depth (Fig. 11b).

\section{Discussion}

\subsection{Validity of 3D models and comparis on to geological maps and cross-sections.}

The fusion of geological field observations with gravity and magnetic data are valid on a statistical basis, including showing: (i) modelled petrophysical properties comparable with the prior (Figs. 4, 6), (ii) adequate yield of independent samples (Fig. 6), (iii) sufficient exploration of the parameter space $(\hat{R}<1.1$, Table 1$)$, and (iv) convergence as indicated by Geweke scores 30 between -1 and +1 (Fig. 7). Aeromagnetic, gravity and field observations show mean residuals of $\sim 0$ with $2 \sigma$ tails that are a maximum of $\sim 20 \%$ of the total dataset range (Fig. 8c,f). Aeromagnetic residuals are spatially uncorrelated except for a small 
Solid Earth Discuss., https://doi.org/10.5194/se-2019-4

Manuscript under review for journal Solid Earth

Discussion started: 15 January 2019

(c) Author(s) 2019. CC BY 4.0 License.

region in the NW corner of the $13.5 \times 13.5$ area (Fig. 8b), indicating that the model captures relevant variation on the length scales of interest. Gravity residuals are systematically positive in the south, west and north, and negative in the east (Fig. 8e). This is primarily a function of a long-wavelength (i.e. deep) gravity response, whereas themodel aims to capture the shallow subsurface model $(<5 \mathrm{~km})$. Field observation misclassifications are only found within $1 \mathrm{~km}$ of geological boundaries. The discrepancies between field observations and modelled geological units may have resulted from the presence of other geological units (particularly those that are highly magnetic). Additionally, more petrophysical data for the Halfway Gneiss and Durlacher Supersuite may have yielded better priors for the geophysical surveys, which in turn would have corroborated better with the position of geological field observations. Ultimately, the data residuals are sufficiently small to have yielded a reliable model output despite minor discrepancies.

The voxelized posterior distributions of the modelled volume are visually comparable to geological maps and interpreted crosssections made by GSWA (Fig. 2, Fig. 10). At the surface, the NW-SE striking Chalba Shear Zone boundary between the Halfway Gneiss and Durlacher Supersuite and the ellipsoidal inlier of Durlacher Supersuite are effectively captured in the models, with predominantly $<1 \mathrm{~km}$ of $<95 \%$ confidenceregions separating $>95 \%$ certainty domains (Fig. 10 ). However, there is an additional $\sim 1 \mathrm{~km}$ wide NW-SE spur of Durlacher Supersuite immediately south of the main portion of the Chalba Shear Zone that is not captured in the models. Additionally, a thin sliver of mapped Durlacher Supersuite that encroaches themap in the NW section of the map (at $\sim 7255500 \mathrm{mN}$ ) is modelled as Halfway Gneiss (Fig. 10), which explains why an abnormally high magnetic residual is present there (Fig. 8). Both of these discrepancies are probably a result of the aeromagnetic data integrating the magnetic response of Halfway Gneiss at depth. For example, in the GSWA cross-section across the NW-SE

20 spur of Durlacher Supersuite, this NW-SE spur is interpreted to be underlain by Halfway Gneiss at depths below 2 km (Fig. 2, Fig. 10).

In three-dimensions, the model maintains the sub-vertical to steeply-dipping regions of $<95 \%$ certainty (i.e., geological boundaries; Fig. 11). This is particularly well viewed in the $\mathrm{X}-\mathrm{Y}$ cross-section, where the posterior distributions reveal subvertical dips $\left(>85^{\circ}\right)$ that are comparable to the sub-vertical dips measured in the field and propagated into interpreted crosssections (Fig. 2, Fig. 10). The modelled inclinations at $4 \mathrm{~km}$ depth are shallower $\left(72^{\circ}\right)$ than those interpreted by GSW A, which maintain dips of $>85^{\circ}$ at $4 \mathrm{~km}$ (Fig. 2). Seismic interpretation data indicates that the Chalba Shear Zone is dipping at $\sim 65^{\circ}$ at $4 \mathrm{~km}$ depth (Fig. 2), more comparable to our modelled dips that those interpreted from geological mapping. However, with the lack of drill hole data, it is difficult to know exactly whether the dips obtained fromseis mic interpretations, geological crosssection interpretation or modelled posterior distributions are correct. Despite these small discrepancies, the broad architecture of the model maintains the framework inferred from geological maps and cross-sections. Importantly, our method is the only technique that provides a range of solutions and quantitatively accounts for all the input assumptions. 
Solid Earth Discuss., https://doi.org/10.5194/se-2019-4

Manuscript under review for journal Solid Earth

Discussion started: 15 January 2019

(c) Author(s) 2019. CC BY 4.0 License.

Another important output is that the modelled posterior distributions reveal that the Durlacher Supersuite is definitively separated into two domains, one NE of the Chalba Shear Zone and the other as an ellipsoidal inlier, with a 2.5 km-wide spur of $>95 \%$ confidence Halfway Gneiss separating thetwo regions (Fig. 10). This model output is corroborated at the surface by geological mapping across the region (Fig. 2) but it was difficult to know whether this spur of Halfway Gneiss between the

5 two Durlacher Supersuite domains continued at depth or was truncated in the near subsurface. Our results indicate that the spur of Halfway Gneiss continues until at least $4 \mathrm{~km}$ as as sumed fromgeological mapping. This important contribution shows that small geological volumes on the scale of a few $\mathrm{km}$ can be resolved accurately and will be important when this modelling output is up-scaled to larger regions.

\section{$10 \quad 5.2 \quad$ Implications and limitations for quantification of uncertainty in 3D geological models}

To develop robust 3D geological models, fusion of geological and geophysical data in a fully probabilistic (Bayesian) method are vital for pure (e.g., plate reconstructions) and applied geological problems (e.g., mineral exploration). At the surface and near-surface $(1 \mathrm{~km})$, our model results are highly similar to independently-constrained geological maps and interpreted crosssections (Fig. 2, Fig. 10), which are us eful for mineral exploration applications that rarely exceed economic deposit depths of

$151 \mathrm{~km}$ (McFadden et al., 2012). At the surface, distances between domains of $>95 \%$ confidence rarely exceed $1 \mathrm{~km}$, although the eastern part of the ellipsoidal Durlacher Supersuite inlier are as wide as $\sim 2350 \mathrm{~m}$. The minimum horizontal distance of $<95 \%$ uncertainty at geological boundaries appears is $\sim 400 \mathrm{~m}$, which appears to be inherently linked to the line spacing of the aeromagnetic survey. Given that the gravity survey and geological field observations are far more widely spaced, and therefore have less control on the model outputs, the aeromagnetic data distribution is probably the dominant control on the width of uncertain regions. So, if higher resolution geophysical surveys and/or geological field observations are acquired, the model can then become more precise. For geological mapping applications (particularly in themineral exploration sector), geological mapping in these uncertain regions (if outcrop is available) and/or high-resolution geophysical surveys across these small regions of uncertainty provide targeted and cost-effective methods of yielding better 3D geological models. Where such regions are under cover and drilling is required to establish formation contacts, our results also aid in constraining which areas should be drilled first to maximize information gain.

For deep applications (e.g., depth to sedimentary basement or depth to Moho), our models require Bayesian incorporation of additional geophysical and geological data, such as active seismic (Johnson et al., 2013), passive seismic (Zhu and Kanamori, 2000) or drill hole geological observations (Beardsmore et al., 2016; McCalman et al., 2014). The incorporation of structural measurement at the surface and in drill core (e.g., faults, folds) could also aid in in informing the prior, particularly when seismic data is unavailable, to provide geologically-feasible models at the surface and shallow subsurface. Other geophysical surveys (e.g., magnetotellurics, radiometrics) could significantly improve the model certainty by identifying other variables in which geological units can have different rock properties. 
Solid Earth Discuss., https://doi.org/10.5194/se-2019-4

Manuscript under review for journal Solid Earth

Discussion started: 15 January 2019

(c) Author(s) 2019. CC BY 4.0 License.

The similarity of geophysical responses from different geological units in terranes that are broadly granitic (e.g., Halfway Gneiss and Durlacher Supersuite) has meant that thetime to reach convergence is significantly greater than studies with units that display vastly different rock properties (Beardsmore et al., 2016; McCalman et al., 2014). The limiting factor is the ability

5 to explore very high-dimensional posteriors that result from a large-scale non-parametric model (i.e. the number of control points at a given resolution scales exponentially with area). Our modelled area is $13.5 \times 13.5 \mathrm{~km}$, which is useful for localscale mineral exploration or detailed geological mapping, but may not be us eful for reconnais sance-scale mineral exploration or terrane-scale geological modelling. Although our convergence times are not prohibitive for up-scaling the model to, for example $100 \times 100 \mathrm{~km}$, computational time becomes difficult for developing 3D geological models for significantly larger areas (e.g., the entire Gascoyne Province). Incorporation of other datatypes (s ee above) may be part of the solution but these all rely on hand sample petrophysical measurements, which are not routinely collected, let alone often reported in the geosciences. To solve the paucity of petrophysical data compared to geophysical surveys, the MCMC sampler could be modified to a reversible jump scheme (Green, 1995; Sambridge, 2013), which is able to define thenumber of layers, sampling over rock categories to define a baseline prior irrespective of available rock property data.

15

An important limitation relates to the confidence of geological field observations. This study has simplified the probability distribution of each field observation to a single beta-binomial distribution, when different supporting data (age, geochemistry, sample descriptions) will provide different likelihoods. Probability distributions of samples that have, for example, age and geochemical data, should be significantly more confident than samples that only havehand sample descriptions. However, the exact range of probabilities to ascribe to these samples still requires some user input. To make this process Bayesian and fully remove operator bias in assigning probabilities to field observations, an independent study will need to be conducted that purely assesses the likelihood of geological field observations, taking into account information like age data, geochemistry data and sample descriptions.

25 Another limitation of the current model is that only two geological units are modelled. In this study, the rationale for such a simplification is that the Halfway Gneiss and Durlacher Supersuite comprise $>90 \%$ of the surface geological units (Fig. 2) but this will rarely be the case in other problems. Integration of volumetrically-minor geological units may be vitally important with respect to mineral exploration or unravelling tectonic histories (e.g., Li-bearing pegmatites; Kesler et al., 2012). A major impediment to effectively modelling these volumetrically-minor units is the line spacing for different geophysical surveys and the potential paucity of geological field observations. In areas that are covered by shallow regolith or sedimentary cover, the problem of modelling volumetrically-minor units is exacerbated due to unavailability of geological surface measurements. Here, the only solution is to have drill hole geological information. Integration of drill hole geological units is already possible to build into the modelling process but moderately deep (>100 m) drill hole data is lacking for the modelled part of the GascoyneProvince. 
Solid Earth Discuss., https://doi.org/10.5194/se-2019-4

Manuscript under review for journal Solid Earth

Discussion started: 15 January 2019

(c) Author(s) 2019. CC BY 4.0 License.

(c) (1)

Conclusions

Bayesian integration of geological field observations with geophysical survey data yield statistically-reliable and geologicallyplausible 3D models at the surface and shallow subsurface $(<4 \mathrm{~km})$. Approximately $89 \%$ of the model area has $>95 \%$ certainty.

5 Regions of $<95 \%$ certainty are found exclusively within $1 \mathrm{~km}$ of mapped or inferred geological boundaries. The widths and positions of regions with $<95 \%$ certainty are primarily a cons equence of lack of geophysical, petrophysical or geological data. Our results indicate that these widths of these uncertain regions can be reduced by targeted geophysical surveys, petrophysical data collection and/or geological mapping. The integration of drill hole geological data and geophysical surveys with higher wavelengths (e.g., active seismic) are required to model deeper into the Earth's crust. Ultimately, the fusion of surface geological observations with geophysical data yield robust 3D geological models with narrow uncertainty regions at the surface and shallow subsurface that will be especially valuable for mineral exploration and the development of 3D geological models under cover.

\section{Code and data availability}

Aeromagnetic survey (Geological Survey of Western Australia, 1996) and gravity (Mathews and Jecks, 2010) data and

15 metadata is freely available from the Geophysical Archive Data Delivery System(www.geoscience.gov.au/geophysical-datadelivery). Petrophysical data are from Aitken et al. (2014). Geological field observations are available from WAROX, a database managed by the Geological Survey of Western Australia (GSWA). Geological field observation data may be directly requested from GSWA.

Model code is stored on GitHub (link to be confirmed)

\section{Author contribution}

HKHO, RC, CC, SR and RDM designed the project. RS and DK developed the experiments, model code and performed the simulations. HKHO prepared themanuscript with contributions fromall co-authors.

\section{Acknowledgements}

25 This research was funded by the Science and Industry Endowment Fund as part of The Distal Footprints of Giant Ore Sys tems: UNCOVER Australia Project (RP04-063) — Capricorn Distal Footprints. 
Solid Earth Discuss., https://doi.org/10.5194/se-2019-4

Manuscript under review for journal Solid Earth

Discussion started: 15 January 2019

(c) Author(s) 2019. CC BY 4.0 License.

(c) (1)

\section{Competing interests}

The authors declare that they have no conflict of interest.

\section{References}

Abedi, M. and Norouzi, G.-H.: Integration of various geophysical data with geological and geochemical data to determine

5 additional drilling for copper exploration, Journal of Applied Geophysics, 83, 35-45, 2012.

Aitken, A. R. A., Joly, A., Dentith, M. C., Johnson, S. P., Thorne, A. M., and Tyler, I. M.: 3D architecture, structural evolution, and mineral prospectivity of the Gascoyne Province: Report 123, Geological Survey of Western Australia, Perth, Australia, 2014. 2014.

Andrieu, C. and Thoms, J.: A tutorial on adaptive MCMC, Statistics and computing, 18, 343-373, 2008.

10 Backus, G.: Inference from Inadequate and Inaccurate Data, I, Proceedings of the National Academy of Sciences, 65, 1-7, 1970.

Beardsmore, G., Durrant-Whyte, H., McCalman, L., O’Callaghan, S., and Reid, A.: A Bayesian inference tool for geophysical joint inversions, ASEGExtended Abstracts, 2016, 1-10, 2016.

Bosch, M., Meza, R., Jiménez, R., and Hönig, A.: Joint gravity and magnetic inversion in 3D using Monte Carlo methods, 15 GEOPHYSICS, 71, G153-G156, 2006.

Brooks, S., Gelman, A., Jones, G., and Meng, X.-L.: Handbook of markov chain monte carlo, CRC press, 2011.

Brooks, S. P. and Gelman, A.: General methods for monitoring convergence of iterative simulations, Journal of computational and graphical statistics, 7, 434-455, 1998.

Cawood, P. A. and Korsch, R. J.: Assembling Australia: Proterozoic building of a continent, Precambrian Research, 166, 120 35, 2008.

Chandra, R., Müller, R. D., Deo, R., Butterworth, N., Salles, T., and Cripps, S.: Multi-core paralleltempering Bayeslands for basin and landscape evolution, arXiv preprint arXiv:1806.10939, 2018. 2018.

Cotter, S. L., Roberts, G. O., Stuart, A. M., and White, D.: MCMC methods for functions: modifying old algorithms to make themfaster, Statistical Science, 2013. 424-446, 2013.

25 Cowles, M. K. and Carlin, B. P.: Markov chain Monte Carlo convergence diagnostics: a comparative review, Journal of the American Statistical Association, 91, 883-904, 1996. 
Solid Earth Discuss., https://doi.org/10.5194/se-2019-4

Manuscript under review for journal Solid Earth

Discussion started: 15 January 2019

(c) Author(s) 2019. CC BY 4.0 License.

(c) (i)

de la Varga, M., Schaaf, A., and Wellmann, F.: GemPy 1.0: open-source stochastic geological modeling and inversion, 2018. 2018.

Dentith, M. and Mudge, S. T.: Geophysics for the mineral exploration geoscientist, Cambridge University Press, 2014.

Earl, D. J. and Deem, M. W.: Parallel tempering: Theory, applications, and new perspectives, Physical Chemistry Chemical 5 Physics, 7, 3910-3916, 2005.

Gallagher, K., Charvin, K., Nielsen, S., Sambridge, M., and Stephenson, J.: Markov chain Monte Carlo (MCMC) sampling methods to determine optimal models, model resolution and model choice for Earth Science problems, Marine and Petroleum Geology, 26, 525-535, 2009.

Gelman, A. and Rubin, D. B.: Inference from iterative simulation using multiple sequences, Statistical science, 7, 457-472, 1992.

Gelman, A., Stern, H. S., Carlin, J. B., Dunson, D. B., Vehtari, A., and Rubin, D. B.: Bayesian data analysis, Chapman and Hall/CRC, 2013.

Geological Survey of Western Australia: Bangemall Basin, Job Number 2048, Perth, Western Australia, 1996.

Geweke, J.: Evaluating the accuracy of sampling-based approaches to the calculation of posterior moments, Federal Res erve

Bank of Minneapolis, Res earch Department Minneapolis, MN, USA, 1991.

Geyer, W.: The importance of suppression of turbulence by stratification on the estuarine turbidity maximum, Estuaries and Coasts, 16, 113-125, 1993.

Giraud, J., Lindsay, M., Ogarko, V., Jess ell, M., Martin, R., and Pakyuz-Charrier, E.: Integration of geological uncertainty into geophysical inversion by means of local gradient regularization, Solid Earth, doi: doi.org/10.5194/se-2018-79, in review. in review.

Giraud, J., Pakyuz-Charrier, E., Jessell, M., Lindsay, M., Martin, R., and Ogarko, V.: Uncertainty reduction through geologically conditioned petrophysical constraints in joint inversionConditioned petrophysical constraints, Geophysics, 82 , ID19-ID34, 2017.

Gradstein, F. M., Ogg, J. G., Schmitz, M.D., and Ogg, G. M., (Eds.): The Geologic Time Scale 2012 2-Volume Set (Vol. 2),

Elsevier, Oxford, U.K., 2012.

Green, P. J.: Reversible jump Markov chain Monte Carlo computation and Bayesian model determination, Biometrika, 82, 711-732, 1995.

Guillaume, B., Ian, L., and Youssef, M.: Bayesian inverse problems with MonteCarlo forward models, Inverse Problems and Imaging, 7, 81-105, 2013. 
Solid Earth Discuss., https://doi.org/10.5194/se-2019-4

Manuscript under review for journal Solid Earth

Discussion started: 15 January 2019

(c) Author(s) 2019. CC BY 4.0 License.

Hapke, C. and Plant, N.: Predicting coastal cliff erosion using a Bayesian probabilis tic model, Marine Geology, 278, 140-149, 2010.

Hastings, W. K.: Monte Carlo sampling methods using Markov chains and their applications, 1970. 1970.

Hjort, N. L., Holmes, C., Müller, P., and Walker, S. G.: Bayesian nonparametrics, Cambridge University Press, 2010.

5 Hu, Z., Yao, Z., and Li, J.: On an adaptive preconditioned Crank-Nicols on MCMC algorithmfor infinite dimensional Bayesian inference, Journal of Computational Physics, 332, 492-503, 2017.

Hukushima, K. and Nemoto, K.: Exchange Monte Carlo method and application to spin glass simulations, Journal of the Physical Society of Japan, 65, 1604-1608, 1996.

Johnson, S. P., Korhonen, F. J., Kirkland, C. L., Cliff, J. B., Belousova, E. A., and Sheppard, S.: An is otopic perspectiveon

10 growth and differentiation of Proterozoic orogenic crust: From subduction magmatismto cratonization, Lithos, 268-271, 7686, 2017.

Johnson, S. P., Sheppard, S., Rasmussen, B., Wingate, M. T. D., Kirkland, C. L., Muhling, J. R., Fletcher, I. R., and Belousova, E. A.: Two collisions, two sutures: Punctuated pre-1950 Ma ass embly of the West Australian Craton during the Ophthalmian and Glenburgh Orogenies, Precambrian Research, 189, 239-262, 2011.

15 Johnson, S. P., Thorne, A. M., Tyler, I. M., Korsch, R. J., Kennett, B. L. N., Cutten, H. N., Goodwin, J., Blay, O., Blewett, R. S., Joly, A., Dentith, M. C., Aitken, A. R. A., Holzschuh, J., Salmon, M., Reading, A., Heinson, G., Boren, G., Ross, J., Costelloe, R. D., and Fomin, T.: Crustal architecture of theCapricorn Orogen, Western Australia and associated metallogeny, Australian Journal of Earth Sciences, 60, 681-705, 2013.

Joly, A., Porwal, A., and McCuaig, T. C.: Exploration targeting for orogenic gold deposits in the Granites-Tanami Orogen:

Mineral systemanalysis, targeting model and prospectivity analysis, Ore Geology Reviews, 48, 349-383, 2012.

Kaipio, J. and Somersalo, E.: Statistical and computational inverse problems, Springer Science \& Business Media, 2006.

Kass, R. E., Carlin, B. P., Gelman, A., and Neal, R. M.: Markov chain Monte Carlo in practice: a roundtable discussion, The American Statistician, 52, 93-100, 1998.

Kesler, S. E., Gruber, P. W., Medina, P. A., Keoleian, G. A., Everson, M. P., and Wallington, T. J.: Global lithium resources:

Relative importance of pegmatite, brine and other deposits, Ore Geology Reviews, 48, 55-69, 2012.

Korhonen, F. J., Johnson, S. P., Wingate, M. T. D., Kirkland, C. L., Fletcher, I. R., Dunkley, D. J., Roberts, M. P., Sheppard, S., Muhling, J. R., and Rasmussen, B.: Radiogenic heating and craton-margin plate stresses as drivers for intraplate orogeny, Journal of Metamorphic Geology, 35, 631-661, 2017. 
Solid Earth Discuss., https://doi.org/10.5194/se-2019-4

Manuscript under review for journal Solid Earth

Discussion started: 15 January 2019

(c) Author(s) 2019. CC BY 4.0 License.

Krapež, B., Müller, S. G., Fletcher, I. R., and Rasmussen, B.: A tale of two basins? Stratigraphy and detrital zircon provenance of the Palaeoproterozoic Turee Creek and Horseshoe basins of Western Australia, Precambrian Research, 294, 67-90, 2017.

Lindsay, M. D., Jessell, M. W., Ailleres, L., Perrouty, S., de Kemp, E., and Betts, P. G.: Geodiversity: Exploration of 3D geological model space, Tectonophysics, 594, 27-37, 2013.

5 Malinverno, A.: Parsimonious Bayesian Markov chain MonteCarlo inversion in a nonlinear geophysical problem, Geophysical Journal International, 151, 675-688, 2002.

Martin, D. M. and Morris, P. A.: Tectonic setting and regional implications of ca 2.2 Ga mafic magmatism in the southem Hamersley Province, Western Australia, Australian Journal of Earth Sciences, 57, 911-931, 2010.

Mathews, L. R. and Jecks, M. J.: Gascoyne Gravity Survey, Report Number R2010006, Atlas Geophysics, Morley, Westem Australia, 1-93 pp., 2010.

McCalman, L., O’Callaghan, S. T., Reid, A., Shen, D., Carter, S., Krieger, L., Beardsmore, G., Bonilla, E. V., and Ramos, F. T.: Distributed Bayesian geophysical inversions, Stanford University, Stanford, California, February 24-26, 20142014, 1-11.

McFadden, P., Barnicoat, A., Blewett, R. S., Collet, D., Collins, W., Dransfield, M., Fitzgerald, D., Haydon, R., Hough, R, Hronsky, J., McCuaig, C., McWilliams, M., Müller, R. D., Whiting, T., and Woodgate, P.: Searching the Deep Earth: a vision for exploration geoscience in Australia, Australian Academy of Science, Canberra, Australia, 47 pp., 2012.

Merdith, A. S., Collins, A. S., Williams, S. E., Pisarevsky, S., Foden, J. D., Archibald, D. B., Blades, M. L., Alessio, B. L., Armistead, S., Plavsa, D., Clark, C., and Müller, R. D.: A full-plate global reconstruction of the Neoproterozoic, Gondwana Research, 50, 84-134, 2017.

Metropolis, N., Rosenbluth, A. W., Rosenbluth, M. N., Teller, A. H., and Teller, E.: Equation of state calculations by fast computing machines, The journal of chemical physics, 21, 1087-1092, 1953.

Miasojedow, B., Moulines, E., and Vihola, M.: An adaptive parallel tempering algorithm, Journal of Computational and Graphical Statistics, 22, 649-664, 2013.

Mosegaard, K. and Tarantola, A.: Monte Carlo sampling of solutions to inverse problems, Journal of Geophysical Res earch: Solid Earth, 100, 12431-12447, 1995.

25 Mosegaard, K. and Vestergaard, P. D.: A simulated annealing approach to seismic model optimization with sparse prior information, Geophysical Prospecting, 39, 599-611, 1991.

Oladyshkin, S., Class, H., and Nowak, W.: Bayesian updating via bootstrap filtering combined with data-driven polynomial chaos expansions: methodology and application to history matching for carbon dioxide storage in geological formations, Computational Geosciences, 17, 671-687, 2013. 
Solid Earth Discuss., https://doi.org/10.5194/se-2019-4

Manuscript under review for journal Solid Earth

Discussion started: 15 January 2019

(c) Author(s) 2019. CC BY 4.0 License.

Oldenburg, D. W. and Li, Y.: Inversion for applied geophysics: A tutorial, Investigations in geophysics, 13, 89-150, 2005.

Olierook, H. K. H., Sheppard, S., Johnson, S. P., Occhipinti, S. A., Reddy, S. M., Clark, C., Fletcher, I. R., Rasmussen, B., Zi, J.-W., Pirajno, F., LaFlamme, C., Do, T., Ware, B., Blandthorn, E., Lindsay, M., Lu, Y.-J., Crossley, R. J., and Erickson, T. M.: Extensional episodes in the Paleoproterozoic Capricorn Orogen, Western Australia, revealed by petrogenesis and 5 geochronology of mafic-ultramafic rocks, Precambrian Research, 306, 22-40, 2018.

Pakyuz-Charrier, E., Giraud, J., Lindsay, M., and Jessell, M.: Common Uncertainty Research Explorer Uncertainty Estimation in Geological3D Modelling, ASEGExtended Abstracts, 2018, 1-6, 2018.

Pall, J., Chandra, R., Azam, D., Salles, T., Webster, J. M., and Cripps, S.: BayesReef: A Bayesian inference framework for modelling reef growth in response to environmental change and biological dynamics, arXiv preprint arXiv:1808.02763, 2018.

102018

Parker, R. L.: Understanding inverse theory, Annual Review of Earth and Planetary Sciences, 5, 35-64, 1977.

Piechocka, A. M., Gregory, C. J., Zi, J.-W., Sheppard, S., Wingate, M. T. D., and Rasmussen, B.: Monazite trumps zircon: applying SHRIMP U-Pb geochronology to systematically evaluate emplacement ages of leucocratic, low-temperature granites in a complex Precambrian orogen, Contributions to Mineralogy and Petrology, 172, 63, 2017.

15 Raftery, A.E. and Lewis, S. M.: Implementing mcmc, Markov chain Monte Carlo in practice, 1996. 115-130, 1996.

Ramos, F. T., Bonilla, E., McCalman, L., O'Callaghan, S., Reid, A., Uther, W. T. B., Sambridge, M., and Rawling, T.: Bayesian data fusion for geothermal exploration, 2012. 2012.

Rasmussen, B.: Radiometic dating of sedimentary rocks: theapplication of diagenetic xenotime geochronology, Earth-Science Reviews, 68, 197-243, 2005.

20 Refs gaard, J. C., Christensen, S., Sonnenborg, T. O., Seifert, D., Højberg, A. L., and Troldborg, L.: Review of strategies for handling geological uncertainty in groundwater flow and transport modeling, Advances in Water Res ources, 36, 36-50, 2012.

Reid, A., Simon Timothy, O. C., Bonilla, E. V., McCalman, L., Rawling, T., and Ramos, F.: Bayesian Joint Inversions for the Exploration of Earth Resources, 2013 2013, 2877-2884.

Rocca, P., Benedetti, M., Donelli, M., Franceschini, D., and Massa, A.: Evolutionary optimization as applied to inverse 25 scattering problems, Inverse Problems, 25, 123003, 2009.

Rudolf, D. and Sprungk, B.: On a generalization of the preconditioned Crank-Nicols on Metropolis algorithm, Foundations of Computational Mathematics, 18, 309-343, 2018.

Sambridge, M.: Geophysical inversion with a neighbourhood algorithm—II. Appraising the ensemble, Geophysical Joumal International, 138, 727-746, 1999. 
Solid Earth Discuss., https://doi.org/10.5194/se-2019-4

Manuscript under review for journal Solid Earth

Discussion started: 15 January 2019

(c) Author(s) 2019. CC BY 4.0 License.

(c) (i)

Sambridge, M.: A parallel tempering algorithmfor probabilistic sampling and multimodal optimization, Geophysical Joumal International, 196, 357-374, 2013.

Sambridge, M. and Mosegaard, K.: Monte Carlo methods in geophysical inverse problems, Reviews of Geophysics, 40, 3-1, 2002.

5 Sambridge, M. S. and Compston, W.: Mixture modeling of multi-component data sets with application to ion-probe zircon ages, Earth and Planetary Science Letters, 128, 373-390, 1994.

Scalzo, R., Kohn, D., Olierook, H. K. H., Houseman, G., Chandra, R., and Cripps, S.: Efficiency and robustness in Monte Carlo sampling of 3-D geophysical inversions with Obsidian v0.1.2: Setting up for success, Geoscientific Model Development, in review. arXiv:1812.00318v00311, in review.

10 Seifert, D., Sonnenborg, T. O., Refsgaard, J. C., Højberg, A. L., and Troldborg, L.: Assessment of hydrological model predictive ability given multiple conceptual geological models, Water Res ources Res earch, 48, 2012.

Selley, R. C. and Sonnenberg, S. A.: Elements of petroleumgeology, Academic Press, 2014.

Sen, M. K. and Stoffa, P. L.: Bayesian inference, Gibbs' sampler and uncertainty estimation in geophysical inversion, Geophysical Prospecting, 44, 313-350, 1996.

15 Sen, M. K. and Stoffa, P. L.: Global optimization methods in geophysical inversion, Cambridge University Press, 2013.

Shafer, G.: Belief functions and parametric models, Journal of the Royal Statistical Society. Series B(Methodological), 1982. 322-352, 1982.

Shen, W., Ritzwoller, M. H., Schulte-Pelkum, V., and Lin, F.-C.: Joint inversion of surface wave dispersion and receiver functions: a Bayesian Monte-Carlo approach, Geophysical Journal International, 192, 807-836, 2013.

20 Sheppard, S., Bodorkos, S., Johnson, S. P., Wingate, M. T. D., and Kirkland, C. L.: The Paleoproterozoic Capricorn Orogeny: Intracontinental reworking not continent-continent collision, Geological Survey of Western Australia, Report 108, 33p, 2010a.

Sheppard, S., Fletcher, I. R., Rasmuss en, B., Zi, J.-W., Muhling, J. R., Occhipinti, S. A., Wingate, M. T. D., and Johnson, S. P.: A new Paleoproterozoic tectonic history of the eastern Capricorn Orogen, Western Australia, revealed by U-Pb zircon dating of micro-tuffs, Precambrian Research, 286, 1-19, 2016.

25 Sheppard, S., Johnson, S. P., Wingate, M. T. D., Kirkland, C. L., and Pirajno, F.: Explanatory notes for the Gascoyne Province, Geological Survey of Western Australia, Perth, Western Australia, 2010b.

Sheppard, S., Occhipinti, S. A., and Nels on, D. R.: Intracontinental reworking in the Capricorn Orogen, Western Australia: the 1680-1620 Ma Mangaroon Orogeny, Australian Journal of Earth Sciences, 52, 443-460, 2005. 
Solid Earth Discuss., https://doi.org/10.5194/se-2019-4

Manuscript under review for journal Solid Earth

Discussion started: 15 January 2019

(c) Author(s) 2019. CC BY 4.0 License.

(c) (1)

Sheppard, S., Rasmussen, B., Muhling, J. R., Farrell, T. R., and Fletcher, I. R.: Grenvillian-aged orogenesis in the Palaeoproterozoic Gascoyne Complex, Western Australia: 1030-950 Ma reworking of the Proterozoic Capricorn Orogen, Journal of Metamorphic Geology, 25, 477-494, 2007.

Tarantola, A. and Valette, B.: Generalized nonlinear inverse problems solved using the least squares criterion, Reviews of 5 Geophysics, 20, 219-232, 1982.

van Ravenzwaaij, D., Cassey, P., and Brown, S. D.: A simple introduction to Markov Chain Monte-Carlo sampling, Psychonomic bulletin \& review, 25, 143-154, 2018.

Wellmann, J. F. and Regenauer-Lieb, K.: Uncertainties have a meaning: Information entropy as a quality measure for 3-D geological models, Tectonophysics, 526-529, 207-216, 2012.

10 Ye, M., Pohlmann, K. F., Chapman, J. B., Pohll, G. M., and Reeves, D. M.: A model-averaging method for assessing groundwater conceptual model uncertainty, Groundwater, 48, 716-728, 2010.

Zhu, L. and Kanamori, H.: Moho depth variation in southern California from teleseismic receiver functions, Journal of Geophysical Research: Solid Earth, 105, 2969-2980, 2000. 
Solid Earth Discuss., https://doi.org/10.5194/se-2019-4

Manuscript under review for journal Solid Earth

Discussion started: 15 January 2019

(c) Author(s) 2019. CC BY 4.0 License.

(c) $($ i)

\section{Figure Captions}
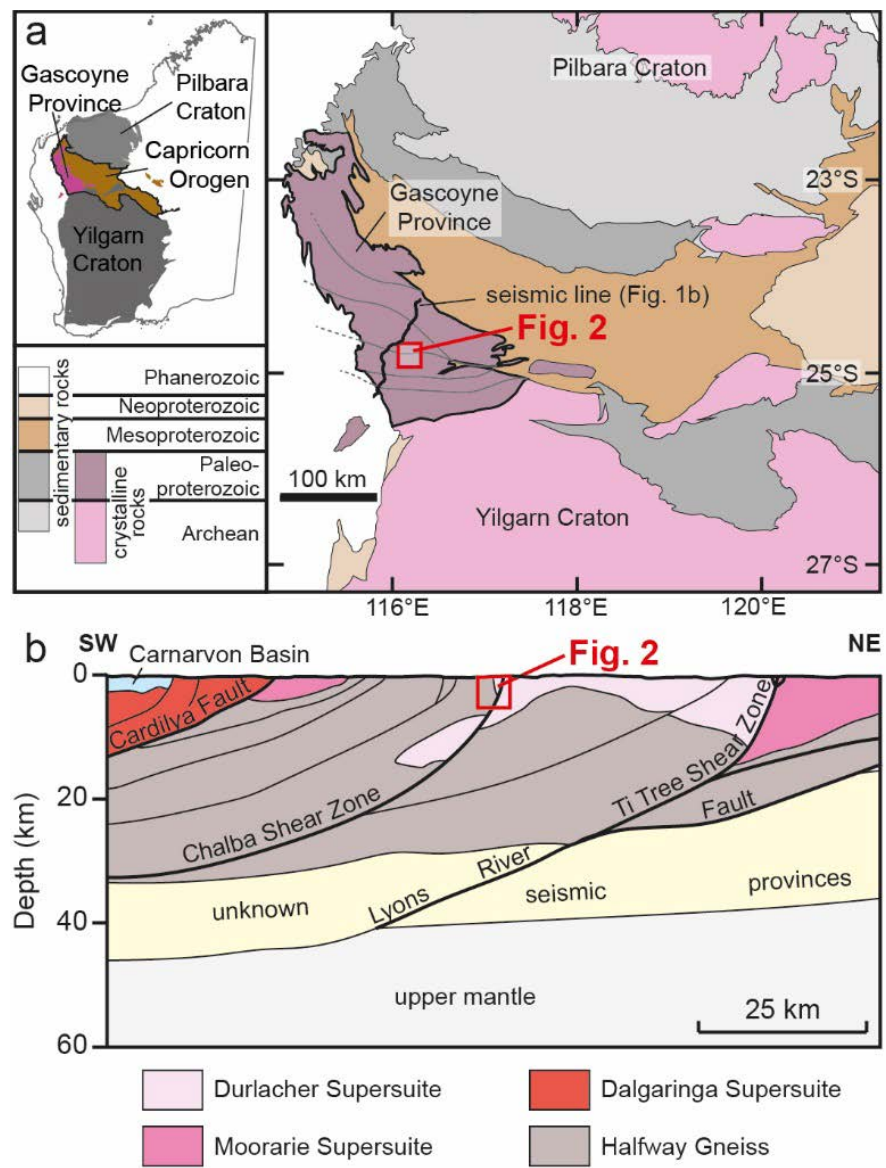

Fig. 1: (a) Geological map of the West Australian C raton, modified from Sheppard et al. (2016), showing location of seismic section. (b) Interpretation of part of seismic line 10GA-CP2, after Johnson et al.(2013). The modelled region in this study is shown on both 5 the map and se ismic section (cf. Fig. 2). 
Solid Earth Discuss., https://doi.org/10.5194/se-2019-4

Manuscript under review for journal Solid Earth

Discussion started: 15 January 2019

(c) Author(s) 2019. CC BY 4.0 License.
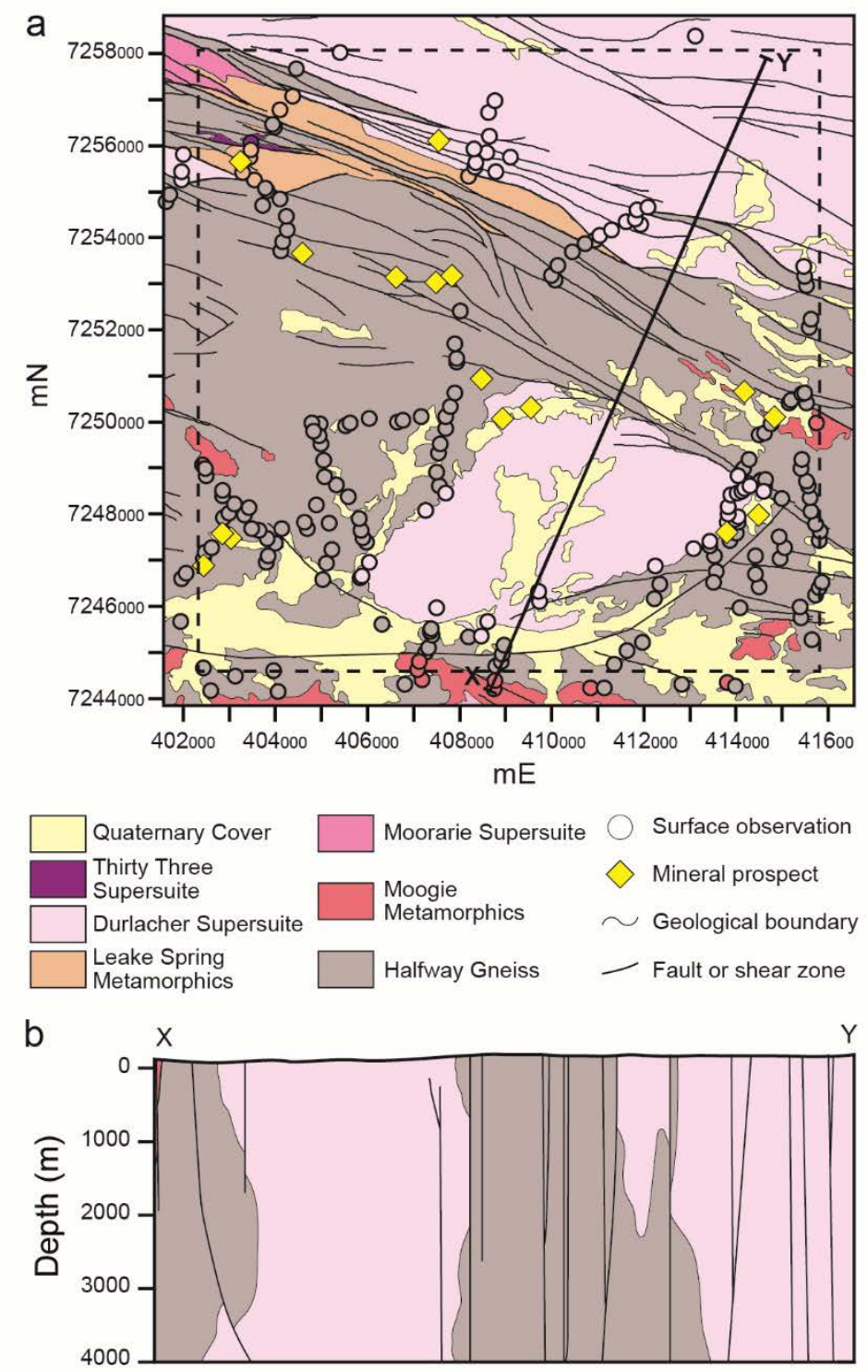

Fig. 2: (a) Detailed geological map of a $15 \times 15 \mathrm{~km}$ portion of the Gascoyne Province with the same centre as the modelled $13.5 \times$ $13.5 \mathrm{~km}$ area (dashed area), showing geological units, structural discontinuities (faults/shear zones), geological surface observations and mineral prospects and deposits. (b) Cross-section through detailed geological map. Map and cross-section compiled using 5 1:100,000 geological maps from the Geological Survey of Western Australia. 
Solid Earth Discuss., https://doi.org/10.5194/se-2019-4

Manuscript under review for journal Solid Earth

Discussion started: 15 January 2019

(C) Author(s) 2019. CC BY 4.0 License.

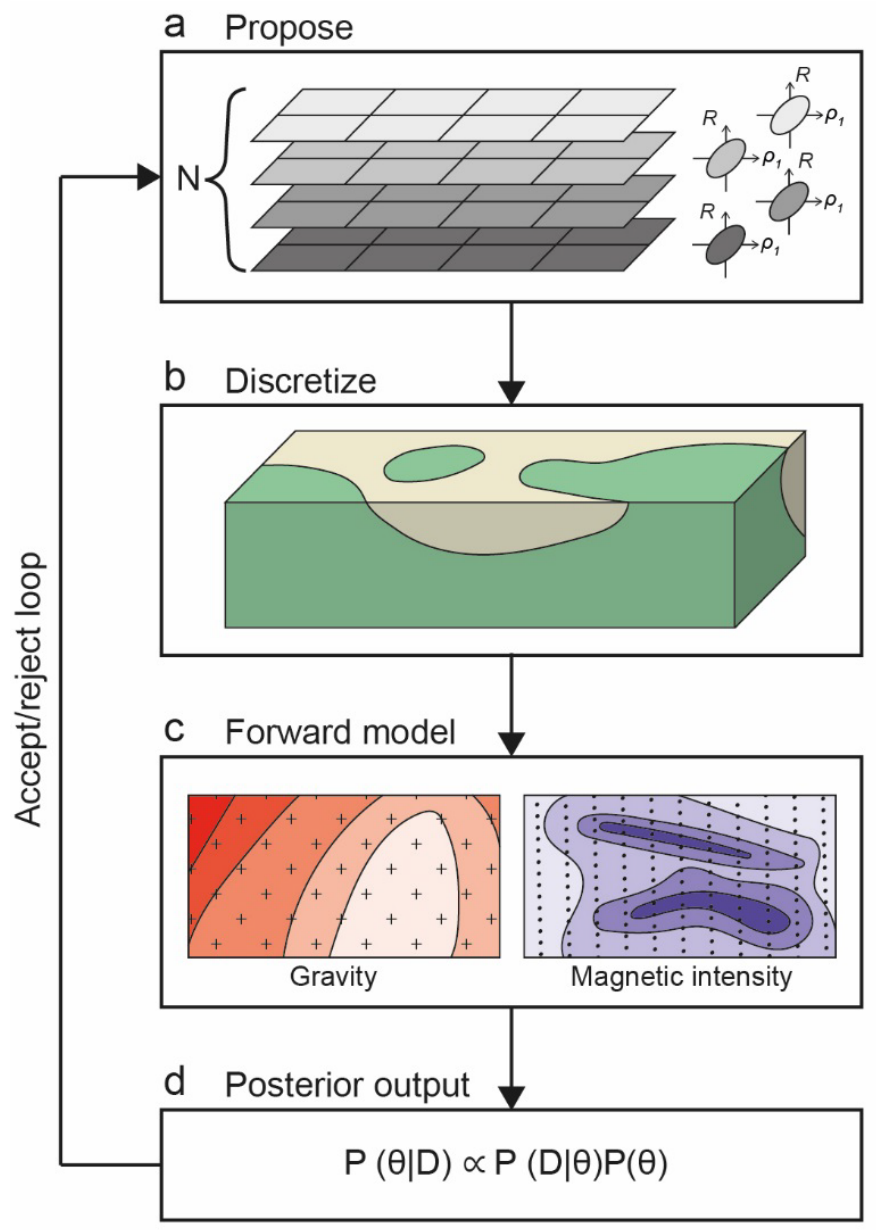

Fig. 3: O bsidian workflow. (a) A set of world parameters, including ge ometry and rock properties for each rock formation included in the 3-D model, is proposed at random representing a small departure from the current parameter set. (b) The se parameters are then rendered to form a discretized 3-D model, from which (c) forward models are calculated to make predictions for the expected readings in each sensor. (d) In the final step, the li kelihood $P(D \mid \theta)$ of the observed datas et given the parameters is calculated, together with the prior probability $P(\theta)$ assigned to th ose parameters. The sample is then accepted or rejected according to the MetropolisHastings criterion, and the process begins again at (a). O ver time the samples from this process will be distributed according to the poste rior probability $P(\theta \mid D)$. 
Solid Earth Discuss., https://doi.org/10.5194/se-2019-4

Manuscript under review for journal Solid Earth

Discussion started: 15 January 2019

(C) Author(s) 2019. CC BY 4.0 License.

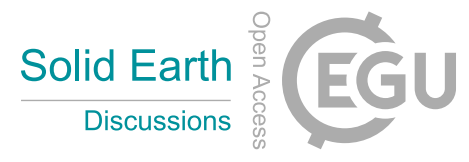

(c) (1)
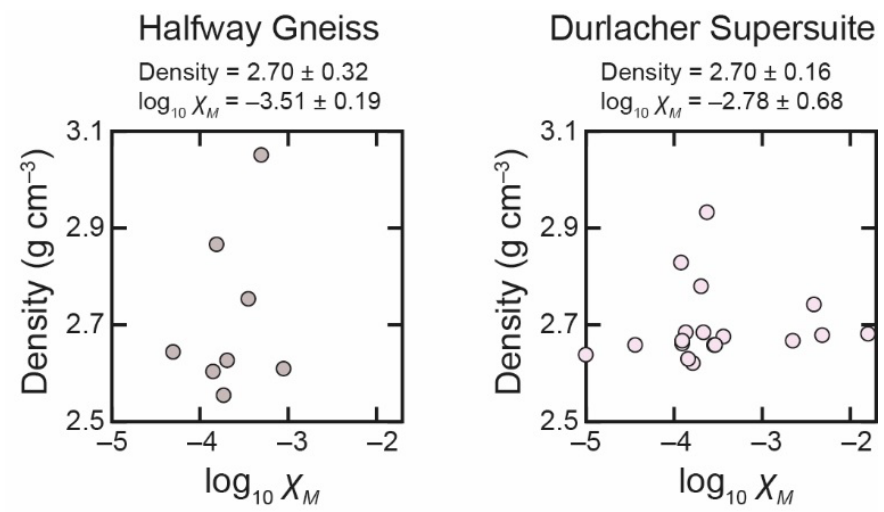

Fig. 4: Measured density and magnetic susceptibility $(\log 10 \chi \mathrm{M})$ for modelled geological units: (a) Halfway Gneiss, (b) Durlacher Supersuite. Mean density and su sceptibility errors are quoted at $2 \sigma$ uncertainty. 
Solid Earth Discuss., https://doi.org/10.5194/se-2019-4

Manuscript under review for journal Solid Earth

Discussion started: 15 January 2019

(C) Author(s) 2019. CC BY 4.0 License.

a

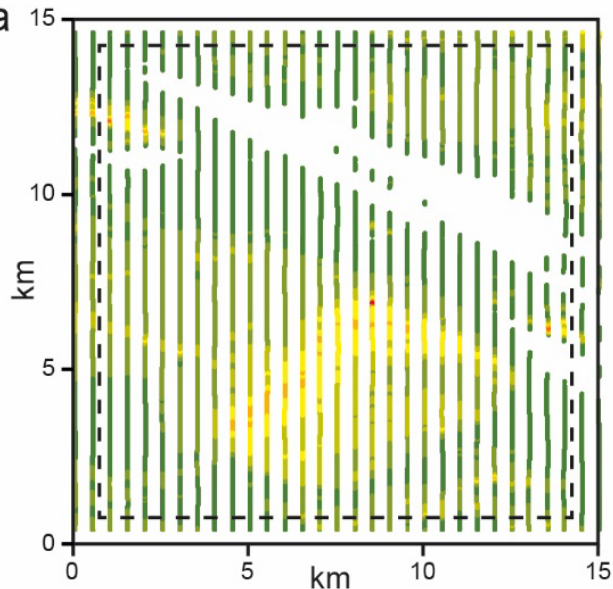

b

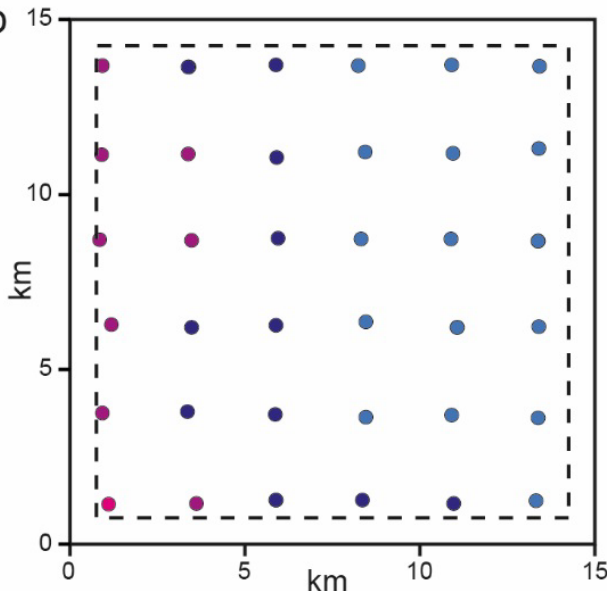

C

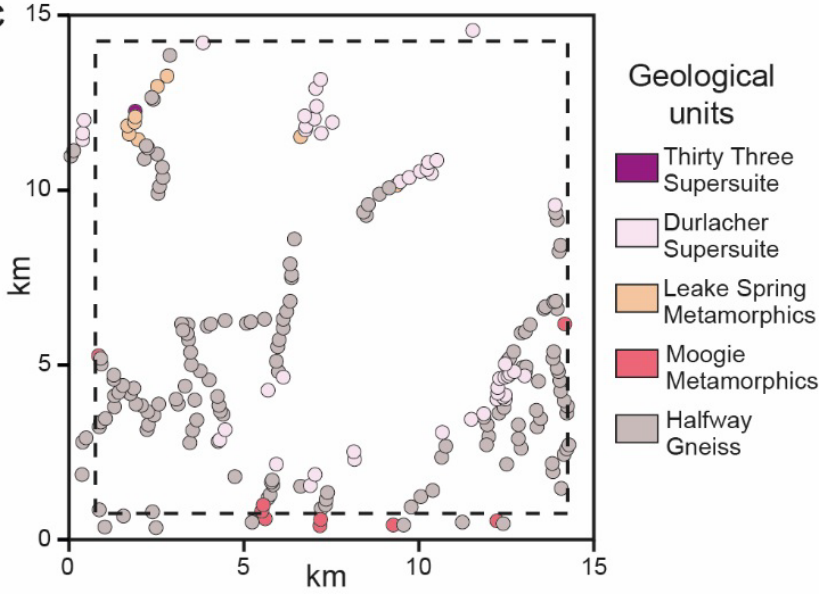

Total magnetic intensity<smiles>[191In]</smiles>

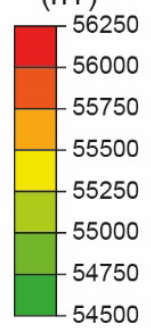

Bouguer gravity anomaly (mGal)

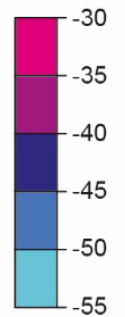

Fig. 5: Measure d ge ophysical survey data and geological field observations for $15 \times 15$ area, with dashed line representing modelled $13.5 \times 13.5 \mathrm{~km}$ area. (a) Aeromagnetic data, showing locations of me asured data on flight lines.(b) Gravity data, showing locations of ground-based measuring stations. (c) Geological field observations. Note the paucity of units other than the Halfway Gneiss and Durlacher Supersuite. 
Solid Earth Discuss., https://doi.org/10.5194/se-2019-4

Manuscript under review for journal Solid Earth

Discussion started: 15 January 2019

(c) Author(s) 2019. CC BY 4.0 License.

(c) (i)
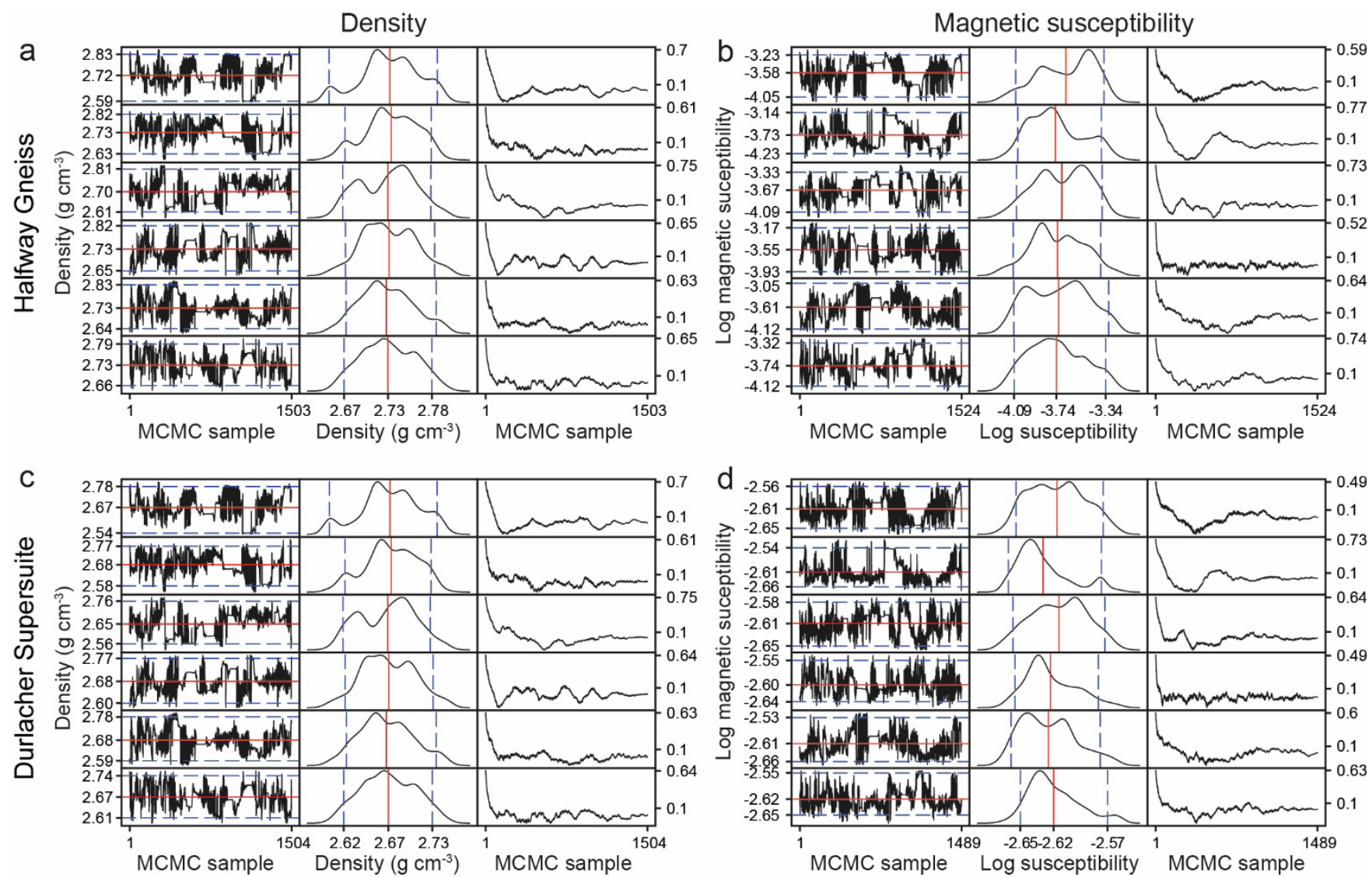

Fig. 6: MCMC diagnostics for the modelled Halfway Gneiss (a,b) and Durlacher Supersuite (c,d), for density (a,c) and magnetic susceptibility (b,d). Column 1 in each panel shows six of the twelve lowest temperature chains. Column 2 in each panel shows the distribution of petroph ysical properties per chain. The red line and blue lines in columns 1 and 2 are the mean and $2 \sigma$, respectively.

5 Column 3 shows the autocorrelation time from the beginning of each chain to the end. Columns 1 and 3 MCMC iterations are thinned by 1000 (i.e., total number of samples is approximately 1.5 million per chain). 
Solid Earth Discuss., https://doi.org/10.5194/se-2019-4

Manuscript under review for journal Solid Earth

Discussion started: 15 January 2019

(C) Author(s) 2019. CC BY 4.0 License.

(c) (i)

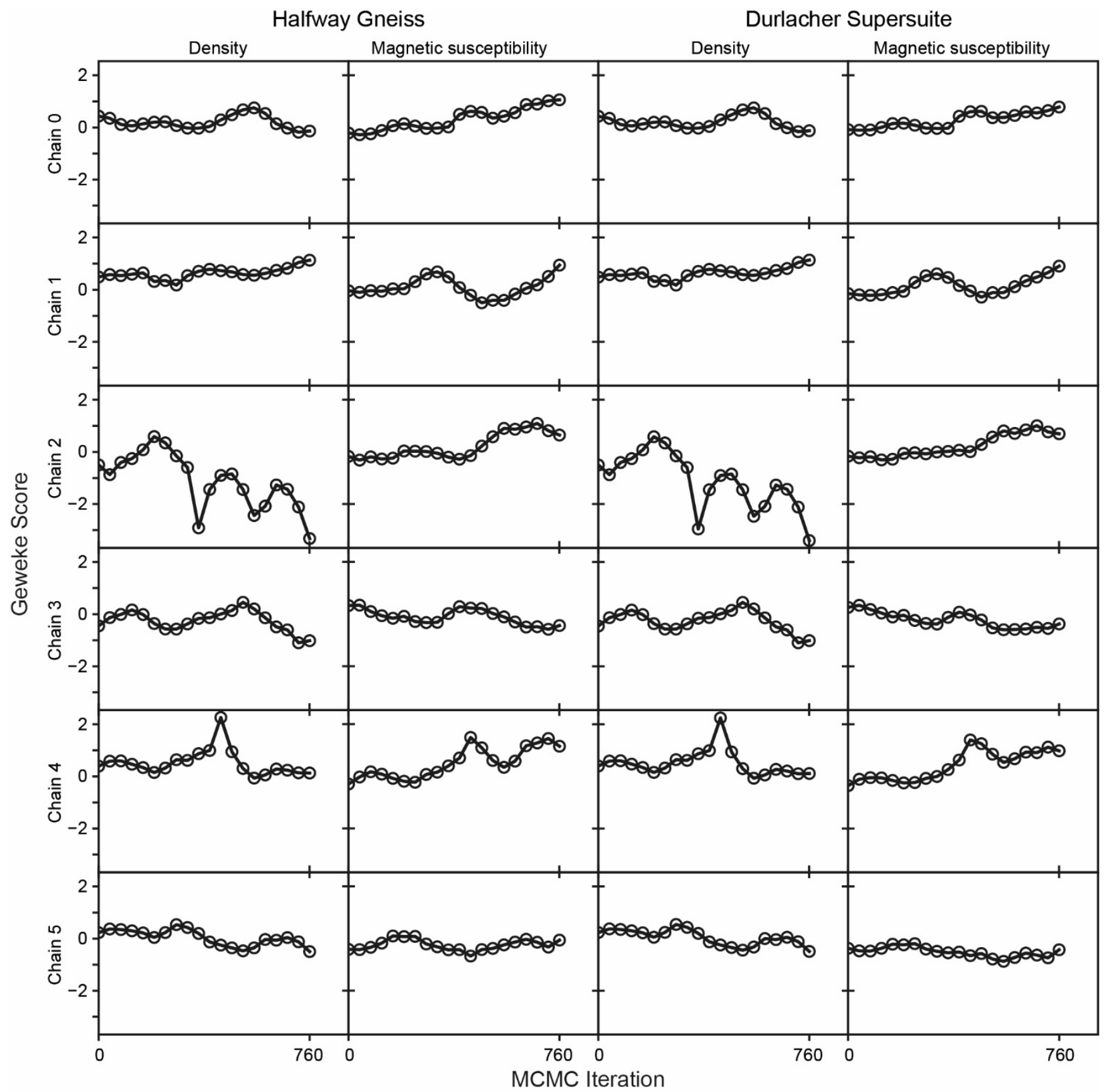

Fig. 7: Geweke scores for modelled densities and magnetic susceptibilities for the Halfway Gneiss and Durlacher Supe rsuite, shown for six chains. 
Solid Earth Discuss., https://doi.org/10.5194/se-2019-4

Manuscript under review for journal Solid Earth

Discussion started: 15 January 2019

(C) Author(s) 2019. CC BY 4.0 License.
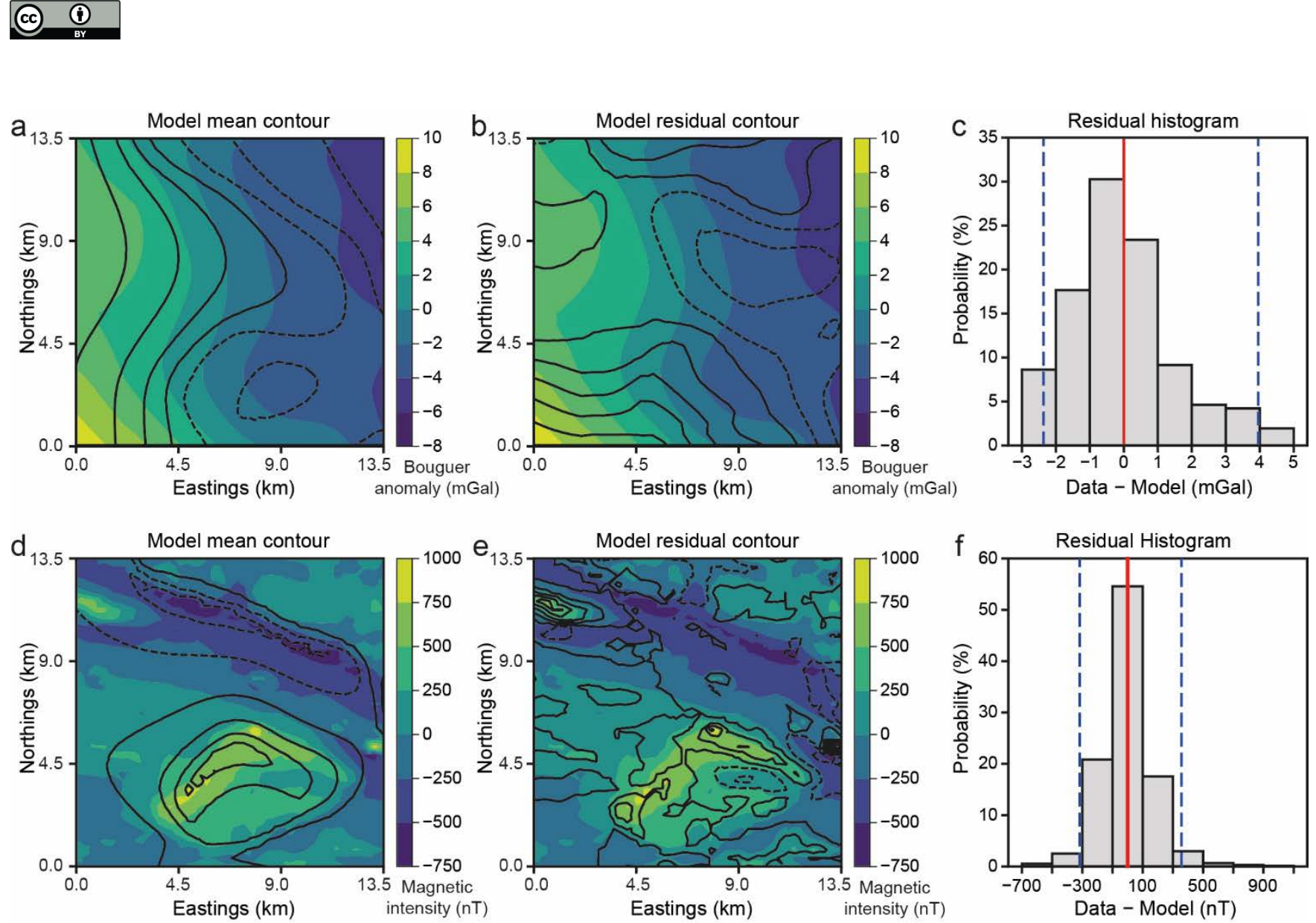

Fig. 8: Modelled Bouguer anomaly and magnetic intensity. Modelled mean contours of (a) Bouguer anomaly and (b) magnetic intensity compared to in terpolated mean colored data. Modelled residual (i.e., data - model) contours for (c) Bouguer anomaly and (d) magne tic intensity compared to interpolated mean colored data. In a-d, contour lines are in $2 \mathrm{mGal}$ and $250 \mathrm{nTincrements} \mathrm{for}$ 5 gravity and magnetic intensity, respectively, where solid lines $\geq 0$ and dashed lines $<0$. Histograms of residuals for (e) Bouguer anomaly and (f) magnetic intensity. 
Solid Earth Discuss., https://doi.org/10.5194/se-2019-4

Manuscript under review for journal Solid Earth

Discussion started: 15 January 2019

(c) Author(s) 2019. CC BY 4.0 License.
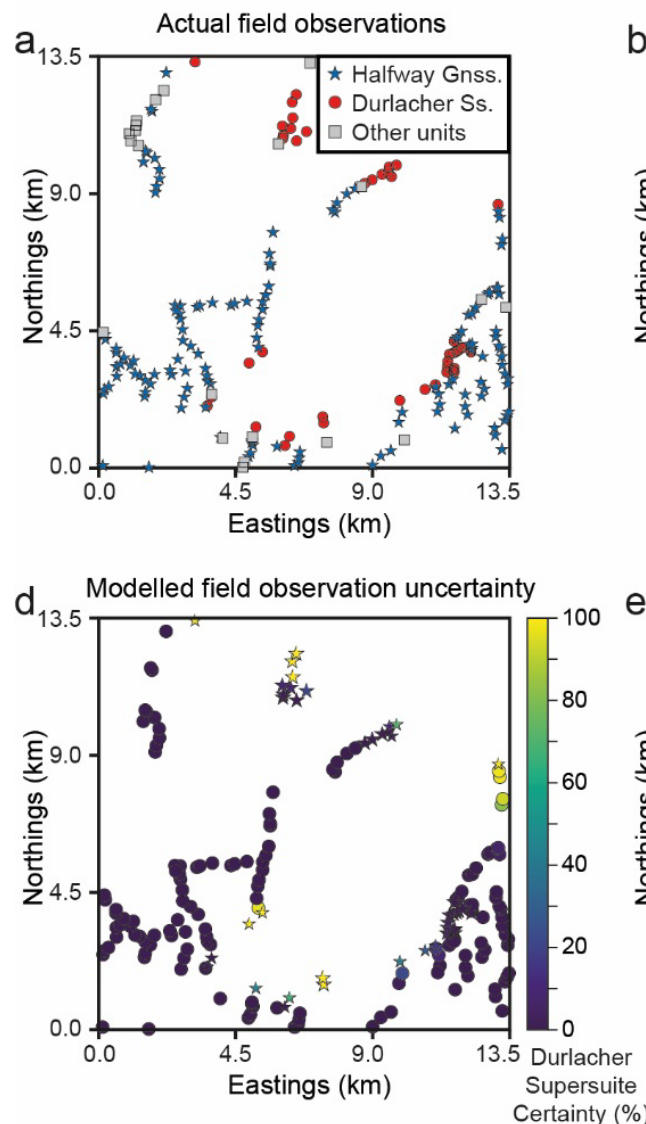

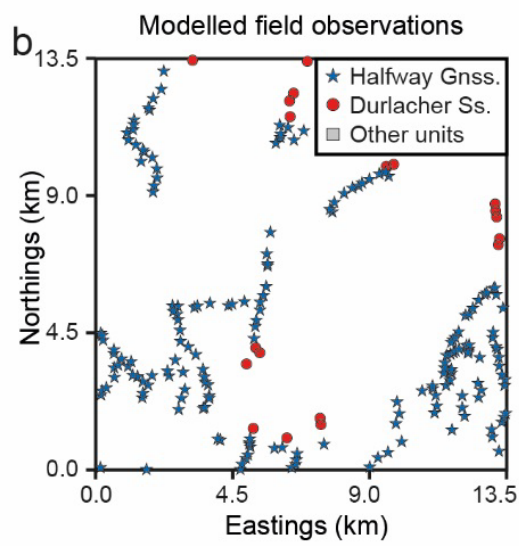

Modelled field observation uncertainty

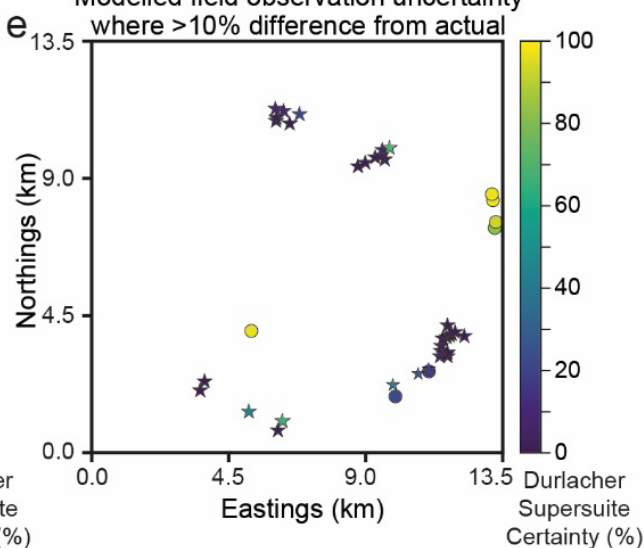

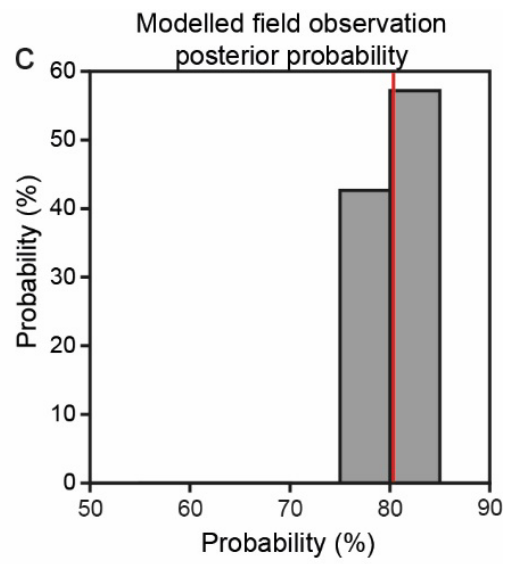

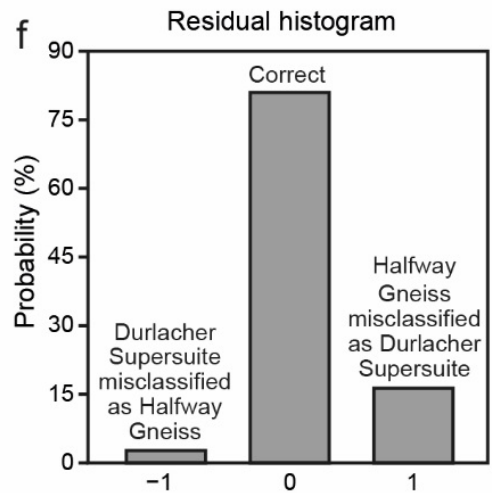

Fig. 9: Actual vs. modelled field observations. (a) Actual field observations. (b) Modelled field observations, showing highest probability geological unit. (c) Modelled field observation posterior probability. (d) Modelled field observations with uncertainty. (e) Modelled field observations with uncertainty, where $>\mathbf{1 0} \%$ different from actual field observations. (f) Residual histogram, where $5-1$ is Durlacher Supersuite misclassified as Halfway Gneiss, 0 is correctly classified and 1 is Halfway Gneiss misclassified as Durlacher Supersuite. 
Solid Earth Discuss., https://doi.org/10.5194/se-2019-4

Manuscript under review for journal Solid Earth

Discussion started: 15 January 2019

(c) Author(s) 2019. CC BY 4.0 License.

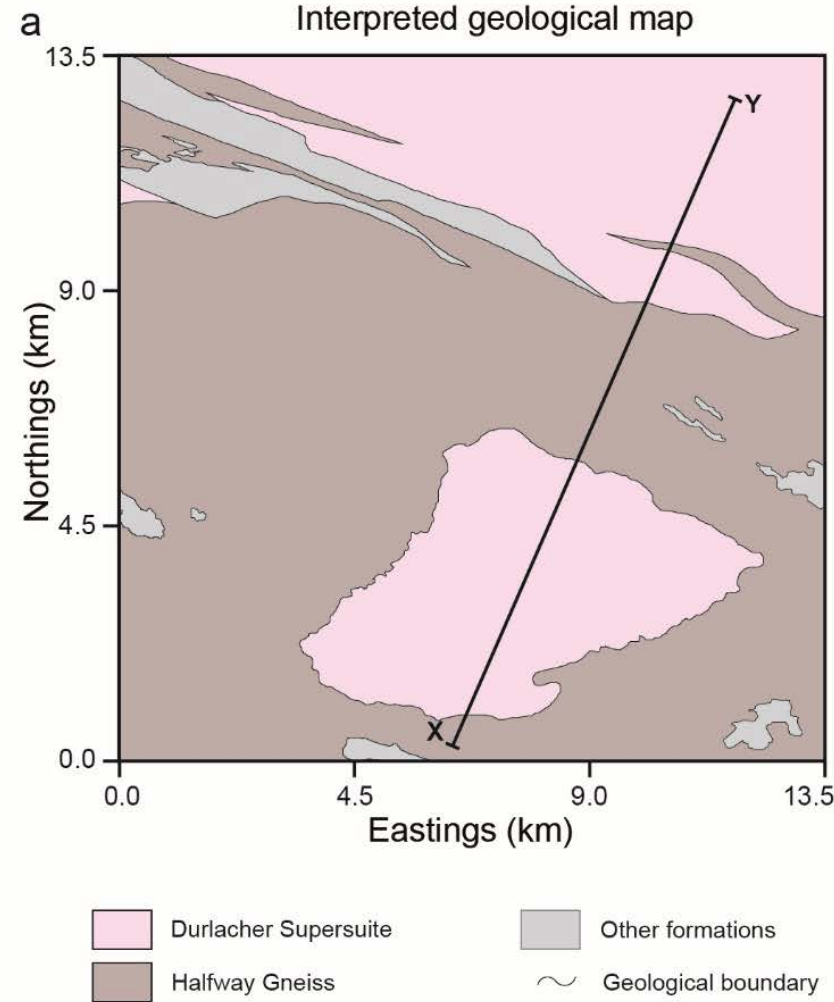

a

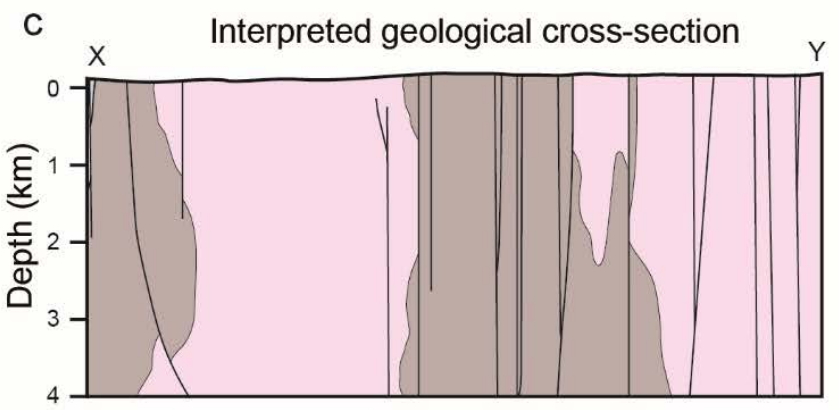

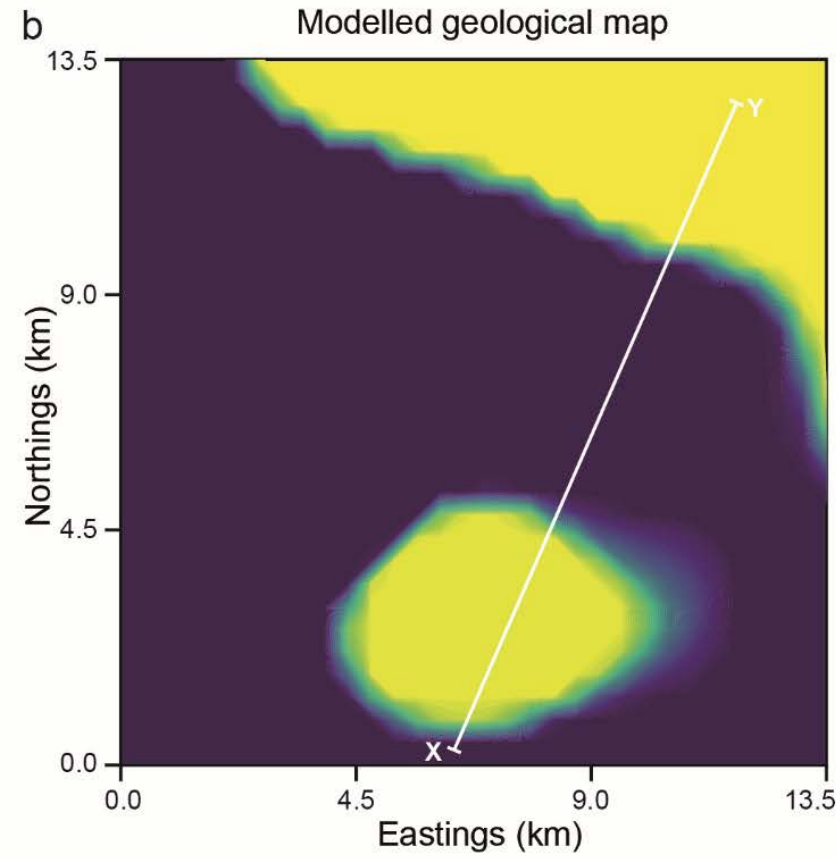

Probability of Durlacher Supersuite (\%)
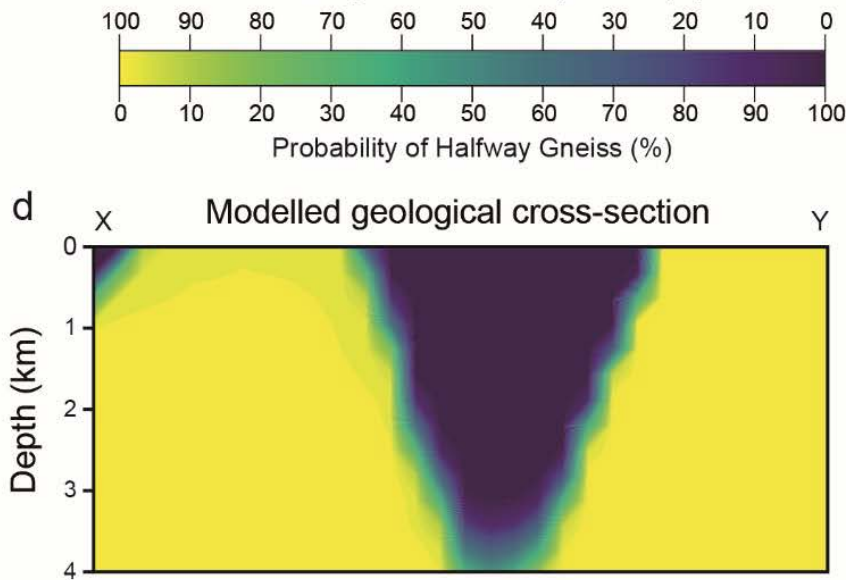

Fig. 10: Voxelized posterior distributions of the 3D geological model compared to simplified GSWA maps and cross-sections. (a) Simplified ge ological map from Figure 2, showing interpreted boundaries for the Durlach er Supe rsuite, Halfway Gneiss and other cross-section through $\mathrm{X}-\mathrm{Y}$ in (b). 
Solid Earth Discuss., https://doi.org/10.5194/se-2019-4

Manuscript under review for journal Solid Earth

Discussion started: 15 January 2019

(c) Author(s) 2019. CC BY 4.0 License.

(c) (1)

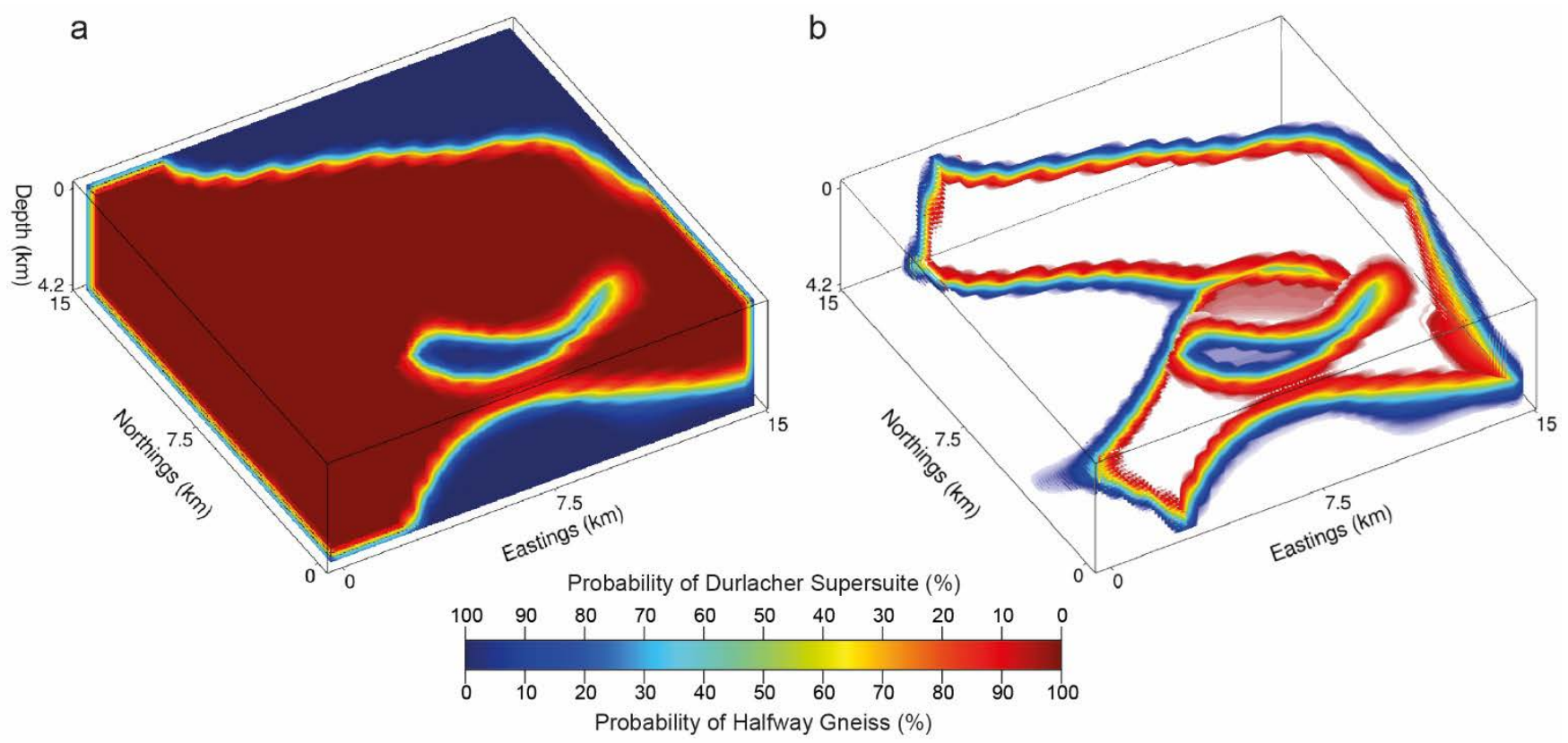

Fig. 11: Voxelized posterior distributions in 3D, looking towards the northeast. (a) Probability of Halfway Gneiss and Durlacher Supersuite. (b) Same as (a) but only showing regions between 5 and $95 \%$ probability (i.e., the interface between Durlacher Supersuite.

\begin{tabular}{|c|c|c|c|c|c|c|}
\hline $\begin{array}{c}\text { Formation, petrophysical } \\
\text { property }\end{array}$ & Mean & $-2 \sigma$ & $+2 \sigma$ & $\begin{array}{l}\text { correlation } \\
\text { time }\end{array}$ & Effective $\mathbf{n}$ & $\hat{\mathbf{R}}$ \\
\hline Halfway Gneiss, Rock Density (mGal) & 2.72 & 0.13 & 0.11 & 11.61 & 129.1967 & 1.02 \\
\hline Durlacher Supersuite, RockDensity (mGal) & 2.67 & 0.13 & 0.11 & 11.59 & 129.4099 & 1.02 \\
\hline Durlacher Supersuite, Log Susceptibility & -2.61 & 0.05 & 0.09 & 13.32 & 112.6397 & 1.02 \\
\hline
\end{tabular}

Table 1: Rock property diagnos tics for density and magnetic susceptibility for both the Halfway Gneiss and Durlacher Supersuite. 